This item is the archived peer-reviewed author-version of:

Investigating IT governance through the Viable System Model

\title{
Reference:
}

Huygh Tim, De Haes Steven.- Investigating IT governance through the Viable System Model Information systems management - ISSN 1058-0530 - 36:2(2019), p. 168-192

Full text (Publisher's DOI): https://doi.org/10.1080/10580530.2019.1589672

To cite this reference: https://hdl.handle.net/10067/1588190151162165141 


\section{Investigating IT Governance through the Viable System Model}

Tim Huygh, University of Antwerp, Antwerp, Belgium ${ }^{1}$

Steven De Haes, University of Antwerp, Antwerp, Belgium \& Antwerp Management School, Antwerp,

Belgium

${ }^{1}$ Corresponding author. Contact at tim.huygh@uantwerpen.be 


\begin{abstract}
This paper investigates the concept of IT governance through the Viable System Model (VSM). We make a theoretical contribution by discussing why IT governance can continue to achieve its purpose of creating and preserving IT business value. Additionally, we demonstrate how the VSM can be used as a lens to describe and diagnose IT governance from a practical perspective, offering insights in how complexity can be unfolded (at the corporate and the business domain level) and how complexity engineering takes place to handle changing (internal and external) complexity.
\end{abstract}

Keywords: IT governance, Viable System Model (VSM), Management cybernetics, Case study 


\section{INTRODUCTION}

Digital disruption is all around us, and many organizations are actively thinking about digital transformation (Valentine \& Stewart, 2015). The realization is that disruptive technologies can impact individual business models, or even entire sectors, in short timeframes (Valentine \& Stewart, 2013). As a result of this increasing pervasiveness of IT, decision-makers are increasingly facing more IT-related decisions (De Haes \& Van Grembergen, 2015). Disciplines like IT management (more operationallyoriented) and IT governance (more strategically-oriented) developed to assist decision-makers with these issues (ISACA, 2012; Peterson, 2004b). It has been stressed many times that the achievement of IT business value relies heavily on good IT governance (De Haes \& Van Grembergen, 2015; Kearns \& Sabherwal, 2006; Weill \& Ross, 2004; Wu, Straub, \& Liang, 2015). As Weill \& Ross (2004, pp. 3-4) put it: "effective IT governance is the single most important predictor of the value an organization generates from IT.” Next to the potential benefits of good IT governance, there are also potential risks to nonexistent or inappropriate IT governance (Ali \& Green, 2012). For instance, IT governance failure is mentioned in relation to information security breaches (Raghupathi, 2007) and IT investment failure (Davenport, 1998). In summary, organizations have clear incentives to strive for effective IT governance, as this enables the creation and preservation of IT business value (Weill \& Ross, 2004).

Studies leveraging theoretical lenses to study IT governance are rare in the contemporary body of knowledge. Many studies have surfaced over time that provided descriptive accounts of IT governance (e.g. Ali \& Green (2012); De Haes \& Van Grembergen (2009); Huang, Zmud, \& Price (2009); Prasad, Green, \& Heales (2012); Weill \& Ross (2004)). However, the absence of a theoretical lens in such studies makes it difficult to explain from a theoretical point of view why IT governance should be organized a certain way for it to be effective. Scholars in the field of IT governance have however not entirely neglected providing theoretical backdrops. Agency theory and the resource-based view of the firm have been extensively used to motivate the need for IT governance in general, or for specific issues (like the need for board involvement in IT governance) (e.g. Benaroch \& Chernobai (2017); Wu et al. (2015); Winkler \& Brown (2013); Wilkin, Campbell, \& Moore (2013)). While valuable, the theoretical 
backdrops in such studies are however only aimed at motivating, from a theoretical point of view, the need for studying IT governance or its related issues.

This article investigates the concept of IT governance through Beer's Viable System Model (VSM), which is grounded in cybernetics (Beer, 1979, 1981, 1985). The VSM has been applied in IS research before (Richter \& Basten, 2014). While traditionally being used to model organizations (i.e. taking the organization as "system-in-focus”), IS research applied the VSM to a variety of socio-technical systems. Examples include a project management system (Karayaz, Keating, \& Henrie, 2011), complex system architecture (Herring \& Kaplan, 2001), a supply chain system (Laumann \& Rosenkranz, 2008), information security (Gokhale \& Banks, 2004), IS agility (Hobbs \& Scheepers, 2009a), and IT governance (Lewis \& Millar, 2009; Peppard, 2005; Skeivys, 2016).

Peppard (2005) was the first to link the concept of IT governance with the VSM. Based on a participatory research project, he proposes that the VSM can be used in the context of IT governance in three ways: (1) to describe, (2) to diagnose, and (3) to design IT governance. He then conceptually discusses the application opportunities in each of these three areas. Lewis \& Millar (2009) present a conceptual discussion applying the VSM to the corporate governance of IT, which is the strategic layer of IT governance where the board of directors is involved. They take a conceptual deep-dive in discussing several aspects of board-level IT governance while referring to the VSM. Finally, Skeivys (2016) conceptually discusses the common areas of IT governance and cybernetics, using the ISO 38500 standard on the corporate governance of IT and the VSM. In summary, the VSM has been used in relation to IT governance before, albeit strictly conceptually.

The purpose of the present article is twofold. First, theoretical arguments are derived from the VSM and its cybernetic foundations, answering the question why IT governance can continue to achieve its purpose of creating and preserving IT business value. While the above-mentioned prior studies have implied the application potential of the VSM in IS research, including IT governance, we take a step further in rigorously introducing the VSM to develop a more concrete (cybernetics-based) understanding of IT governance. Second, a case study is presented that demonstrates how the VSM can be used as a lens for IT governance from a practical perspective. This allows us to show how complexity can be 
unfolded and how variety engineering takes place to handle changing (external and internal) complexity. Building on Peppard (2005), our study is the first to provide an empirical example of describing and diagnosing IT governance using the VSM, thereby extending the discussion beyond the conceptual level.

The remainder of this paper is structured as follows. Section 2 contains the theoretical background for this research. First, IT governance and the VSM are discussed separately. At the end of this section, the appropriateness of the VSM as a theoretical lens for IT governance is motivated, and theoretical parallels are drawn between the VSM and IT governance. The third section discusses the research design and provides some information on how the case study was conducted. Section 4 presents the case company's IT governance arrangement. The fifth section contains a discussion of investigating this arrangement through the VSM. Finally, section 6 presents concluding remarks, limitations, and opportunities for future research.

\section{THEORETICAL BACKGROUND}

\subsection{IT Governance}

IT governance is a focus area of corporate governance and is concerned with the oversight and control of IT assets, their overall contribution to business value, and the mitigation of IT-related risks (Weill \& Ross, 2004). While there is no agreed-upon definition in the literature for the concept of IT governance, there are more similarities than differences in the various definitions that have been proposed. Van Grembergen \& De Haes (2009, p. 3) started using the term 'enterprise governance of IT' to explicitly indicate that it should operate at the same level as corporate (or enterprise) governance. They define the concept as "an integral part of corporate governance [that] addresses the definition and implementation of processes, structures and relational mechanisms in the organization that enable both business and IT people to execute their responsibilities in support of business/IT alignment and the creation of business value from IT-enabled business investments. ${ }^{2}$

\footnotetext{
2 This definition is based on the ITGI (2003) definition: "IT governance is the responsibility of the board of directors and executive management. It is an integral part of enterprise governance and consists of the leadership and organizational structures and processes that ensure that the organisation's IT sustains and extends the organisation's strategy and objectives." (IT Governance Institute (ITGI), 2003, p. 10)
} 
Early debates framed IT governance as the centralization or decentralization (or a combination of both) of IT-related decision-making authority, and the conditions under which a certain arrangement was chosen (Brown, 1997; Brown \& Renwick, 1996; Sambamurthy \& Zmud, 1999). In contemporary research however, there seems to be consensus that reality is more complex and that an IT governance implementation should consist of structures, processes, and relational mechanisms (De Haes \& Van Grembergen, 2015; Wu et al., 2015). IT governance structures include organizational units and roles responsible for making IT-related decisions and for enabling contacts between business and IT management (decision-making) functions (e.g. IT strategy committee). These are the blueprints of how the IT governance framework will be structurally organized. IT governance processes refer to formalization and institutionalization of strategic IT decision making or IT monitoring procedures, to ensure that daily behavior is consistent with policies and provide input back to decisions (e.g. IT balanced scorecard). IT governance relational mechanisms are about the active participation of, and collaborative relationship among, corporate executives, IT management, and business management and include announcements, advocates, channels and education efforts (De Haes \& Van Grembergen, 2009; Peterson, 2004a; Weill \& Ross, 2004). The implementation of a set of IT governance mechanisms with attention to each of these three categories results in a powerful interconnected IT governance arrangement (Ali \& Green, 2012; De Haes \& Van Grembergen, 2009, 2015; Prasad et al., 2012; Wu et al., 2015).

\subsection{The Viable System Model}

The Viable System Model (VSM) represents a systems thinking approach that emphasizes active learning and control and is therefore particularly useful for systems that are operating in highly uncertain environments (Flood \& Jackson, 1991). Beer developed and described the viable system model in his seminal trilogy, under the general heading of "The managerial cybernetics of organization" (Beer, 1972, 1979, 1981, 1985), often referred to as “Brain” (and its second edition), “Heart”, and "System”. Especially the third book, "System" (Beer, 1985), makes a clear effort to make the VSM and its underpinnings more accessible to practice. The logic behind the VSM is extensively described in these 
three books, as well as by other writers elsewhere (e.g. Espejo \& Harnden (1989); Espejo \& Reyes (2011); Hoverstadt (2010); Yolles (1999)).

The VSM is theoretically grounded in cybernetics. The interdisciplinary science of cybernetics was first formally defined by Norbert Wiener in his seminal book on the subject in 1948, defining it as "[the science of] control and communication in the animal and the machine.” (Wiener, 1948, p. i). A few years later, Ashby positions cybernetics as the science of complex systems (Ashby, 1956). Building on this pioneering work, Beer is talking about 'management cybernetics' (Beer, 1959), stating that: "cybernetics is the science of effective organization" (Beer, 1985, p. ix). As a result, the VSM can be referred to as "a theory of organization" (Anderton, 1989, p. 40). Beer is considered to be the first to translate cybernetic principles to the field of management, ultimately resulting in the VSM (Mingers \& White, 2010). Beer's motivation is stemming from the fact that traditional ways of thinking about management do not embrace the key concept of viability (Beer, 1985).

Figure 1 presents the essence of a viable system. The viable system exists within an environment that imposes a certain complexity on it. Through implementing its purpose (i.e. operation), and controlling this implementation (i.e. management), the viable system seeks to establish requisite variety. Requisite variety is a state that is achieved when environmental, operational, and managerial complexities equate. Since environmental complexity $>$ operational complexity $>$ managerial complexity, establishing requisite variety requires variety engineering. Only when requisite variety is maintained, the system will remain viable (i.e. continue to achieve its purpose). The VSM describes the five necessary and sufficient interconnected subsystems that enable the viable system to self-organize through variety engineering, thereby ensuring its viability. The dashed connection between management and environment represents the communication with the system's environment and the anticipation of possible future states of the system (Beer, 1979, 1981, 1985). 


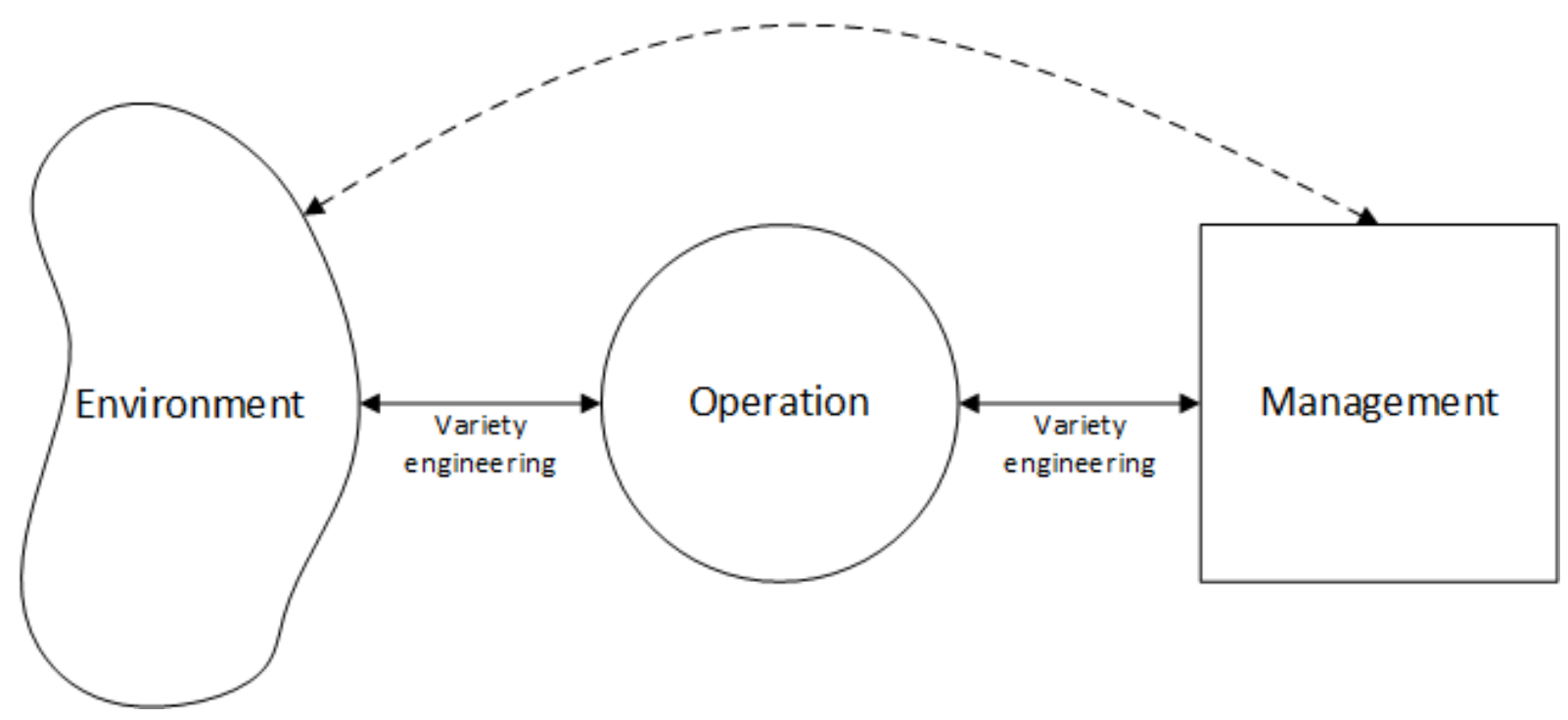

Figure 1. Variety engineering to enable requisite variety between environmental, operational, and managerial complexities (Beer, 1985)

Table 1 discusses the building blocks of any viable system: (1) its underlying concepts, (2) its (sub)systems or functions, and (3) its communication channels or variety loops. It should be noted that this table does not explain every detail of the VSM. For a more detailed discussion, the reader is referred to Beer's original work (Beer, 1979, 1981, 1985) and other reference work (e.g. Espejo \& Harnden (1989); Espejo \& Reyes (2011); Hoverstadt (2010); Yolles (1999)). To summarize, the VSM is a generic and dynamic model of organisation to support the design and diagnosis of effective control and communication structures (Espejo \& Reyes, 2011).

Table 1. VSM underlying concepts, VSM (sub)systems or functions, and VSM communication channels or variety loops

\begin{tabular}{|l|l|}
\hline \multicolumn{2}{|c|}{ VSM underlying concepts } \\
\hline & $\begin{array}{l}\text { The system is capable to maintain itself in a changing environment (Shaw, } \\
\text { Snowdon, Holland, Kawalek, \& Warboys, 2004). This is closely related to the } \\
\text { concept of variety, as a system is said to be viable when it is able to continuously } \\
\text { cope with the variety to which it is imposed (Jackson, 1991). Therefore, a system } \\
\text { can only be viable if it has the capacity to adapt (Espejo, 1989). Indeed, for viable } \\
\text { systems it is important to detect environmental changes quickly and adapt in a way } \\
\text { to meet the variety to which it is exposed at any given time (Pollalis \& Dimitriou, } \\
\text { 2008). }\end{array}$ \\
\hline
\end{tabular}




\begin{tabular}{|c|c|}
\hline $\begin{array}{c}\text { (Requisite) } \\
\text { Variety }\end{array}$ & $\begin{array}{l}\text { Variety is a measure of complexity (Beer, 1979) and threatens to overwhelm a } \\
\text { system's regulators (Beer, 1989). The ability to continuously cope with this variety } \\
\text { implies to be viable. Ashby's law of requisite variety is the fundamental underlying } \\
\text { principle of the VSM. The law states that only variety can absorb variety (Ashby, } \\
\text { 1956, p. 207). In other words, the variety of the controlling element should be at } \\
\text { least as great as the variety of the element that is to be controlled. Therefore, variety } \\
\text { engineering takes place through each communication channel of the viable system } \\
\text { (Beer, 1985). }\end{array}$ \\
\hline Recursivity & $\begin{array}{l}\text { Recursivity refers to the fact that "any viable system contains, and is contained in, } \\
\text { a viable system" (Beer, 1979, p. 118). The VSM is fractal in nature, meaning that } \\
\text { each viable system, at any given level of recursion, can be modelled using exactly } \\
\text { the same syntax (Beer, 1979). This enables consistent modelling at different levels } \\
\text { of granularity. }\end{array}$ \\
\hline Transduction & $\begin{array}{l}\text { Transduction applies to the communication channels of the VSM. It implies that } \\
\text { the communication between two entities should be translated into terms that the } \\
\text { receiving entity understands, while preserving the intended variety (Beer, 1985). }\end{array}$ \\
\hline \multicolumn{2}{|r|}{ VSM (sub)systems or functions } \\
\hline System 1 & $\begin{array}{l}\text { System } 1 \text { is composed of all assets and primary activities that together implement } \\
\text { the purpose of the system (i.e. operational units), and all managerial activity } \\
\text { directly related to this (i.e. local management units). System } 1 \text { of the system-in- } \\
\text { focus is therefore the combination of all embedded viable systems. An embedded } \\
\text { viable system is the combination of an operational unit and a local management } \\
\text { unit (Beer, } 1979,1985 \text { ). }\end{array}$ \\
\hline System 2 & $\begin{array}{l}\text { System } 2 \text { coordinates the system } 1 \text { activities of the system-in-focus. It represents a } \\
\text { process of auto-regulation to deal with oscillations that arise through interactions } \\
\text { between or within embedded viable systems (Beer, 1979). System } 2 \text { mechanisms } \\
\text { can reflect managerial decisions, but do not make them (Beer, 1985). }\end{array}$ \\
\hline System 3 & $\begin{array}{l}\text { System } 3 \text { controls the operation of the system-in-focus (i.e. system } 1 \text { as the set of } \\
\text { all embedded viable systems) (Beer, 1985). It is responsible for keeping the } \\
\text { autonomy of all embedded viable systems in balance with the overall cohesion } \\
\text { (Anderton, 1989). System } 3 \text { is the management function concerned with running } \\
\text { the current state of affairs (Hoverstadt, 2010). }\end{array}$ \\
\hline System 3* & $\begin{array}{l}\text { System } 3^{*} \text { is the audit channel, enabling system } 3 \text { to obtain information directly } \\
\text { from system } 1 \text { operational units (Beer, 1985). }\end{array}$ \\
\hline System 4 & $\begin{array}{l}\text { System } 4 \text { senses opportunities and threats in the system's environment, which } \\
\text { could potentially threaten the system's viability if they were to be undetected } \\
\text { (Espejo, 1989). It is the management function concerned with possible future states } \\
\text { of the system (Hoverstadt, 2010). System } 4 \text { is also engaged in external } \\
\text { communication with the total environment of the system (Beer, 1985). It also holds } \\
\text { and maintains a model of the system itself, enabling the system to be self- } \\
\text { referential (Beer, 1985). }\end{array}$ \\
\hline
\end{tabular}




\begin{tabular}{|c|c|}
\hline System 5 & $\begin{array}{l}\text { System } 5 \text { is the ultimate decision-maker within a recursion of the viable system, } \\
\text { thereby providing logical closure to it (Beer, 1985). It creates and maintains the } \\
\text { system's identity (Beer, 1979) and is therefore responsible for setting its overall } \\
\text { direction, values, and purpose (Espejo \& Gill, 1997). System } 5 \text { also monitors the } \\
\text { S3-S4 homeostat (i.e. the feedback loop between the inside-and-now and the } \\
\text { outside-and-future), to ensure a healthy balance between both management } \\
\text { functions (Beer, 1985; Hoverstadt, 2010). Finally, system } 5 \text { maintains an } \\
\text { understanding of the relationship between the system-in-focus and the systems } \\
\text { within which it is embedded (Hoverstadt, 2010). }\end{array}$ \\
\hline \multicolumn{2}{|r|}{ VSM communication channels or variety loops } \\
\hline $\begin{array}{c}\text { Communication } \\
\text { with the } \\
\text { environment }\end{array}$ & $\begin{array}{l}\text { The system communicates with its environment through system } 1 \text { (i.e. through its } \\
\text { embedded viable systems with its embedded environments), and through system } 4 \\
\text { (i.e. with its total environment). An important aspect of this is the communication } \\
\text { with the future, i.e. sensing opportunities and threats in the system's environment } \\
\text { (Beer, 1979, 1985). }\end{array}$ \\
\hline Command axis & $\begin{array}{l}\text { The command axis provides the metasystem (i.e. the combination of systems } 3,4 \text {, } \\
\text { and 5) with the ability to command and make decisions. Specifically, it consists of } \\
\text { (1) a resource bargaining channel, (2) an accountability channel (i.e. performance } \\
\text { measurement), and (3) an intervention channel (Beer, 1979, 1985; Hoverstadt, } \\
\text { 2010). }\end{array}$ \\
\hline $\begin{array}{c}\text { Algedonic } \\
\text { channel }\end{array}$ & $\begin{array}{l}\text { The algedonic channel is used to transfer algedonic signals, which is information } \\
\text { that requires the immediate attention of the metasystem (Beer, 1979, 1985). }\end{array}$ \\
\hline $\begin{array}{l}\text { S3 - S4 } \\
\text { homeostat }\end{array}$ & $\begin{array}{l}\text { The S3-S4 variety loop represents the balancing act of the relationship between the } \\
\text { present (system 3) and the future (system 4). It concerns decision-making about } \\
\text { (the path to) desired future states of the system, i.e. strategic decision-making } \\
\text { (Hoverstadt, 2010). It is directly monitored by system 5, to ensure compatibility } \\
\text { with the system's overall direction, values, and purpose (Beer, 1985; Espejo \& } \\
\text { Gill, 1997). }\end{array}$ \\
\hline
\end{tabular}

In the IS field, cybernetics is recognized as a theory for explaining and predicting (EP theory). This interdisciplinary grand theory can therefore be applied to study " [...] what is, how, why, when, and what will be [...]” (Gregor, 2006, p. 626). As the VSM is the result of applying cybernetics to organisation, referred to as management cybernetics (Beer, 1959, 1985), the VSM can be classified as an EP theory as well. Richter \& Basten (2014) provide an overview of VSM applications in IS research. Coming up with 13 relevant articles and analysing them in terms of study object, purpose, quality focus, viewpoint of the study's recipients, and study's context; they conclude that "IS research is in need of approaches to deal with complex real-world systems. Relying on systemic approaches like the VSM is a viable and advisable strategy.” (Richter \& Basten, 2014, p. 4597). 


\subsection{The VSM as a Theoretical Lens for IT Governance}

This section links IT governance with the VSM. First, the applicability of the VSM for IT governance is conceptually motivated. Then, theoretical parallels are drawn between the VSM and IT governance, ultimately answering the question why IT governance can continue to achieve its purpose of creating and preserving IT business value.

\subsubsection{Motivating the Applicability of the VSM for IT Governance}

The prior conceptual studies that explicitly apply the VSM in the field of IT governance are rather limited in their arguments related to its applicability. Peppard (2005) puts forward the VSM as a guiding framework for IT governance based on the suggestion of one of the participants in a workshop during the first research cycle of a participatory action research project. He then goes on by motivating that the objectives of the VSM and IT governance are similar (i.e. to provide stability and coherence) and that there seems to be a shared vocabulary between the VSM and IT governance literature. Lewis \& Millar (2009) state that cybernetics and IT governance are both concerned with control and that, since the VSM is grounded in cybernetics, the VSM “[...] may prove a useful starting point for formulating a comprehensive model of IT governance” (Lewis \& Millar, 2009, p. 3). Skeivys (2016) makes a similar argument, stating that control and communication surface in the definitions of both cybernetics and IT governance. Below, the arguments in favor of applying the VSM for studying the IT governance concept are extended.

Contemporary IT governance research recognizes that the earlier centralization versus decentralization of IT-related decision-making authority debate was too simplistic. There is consensus in the state-ofthe-art that reality is more complex, acknowledging that an IT governance arrangement should consist of a powerful whole of interconnected IT governance mechanisms (Ali \& Green, 2012; De Haes \& Van Grembergen, 2009, 2015; Prasad et al., 2012; Wu et al., 2015). The complexity of the underlying system (in this case IT governance) is a focal reason for applying the VSM (Shaw et al., 2004).

Digital disruption and digital transformation is inherent to today's rapidly changing business environment (Valentine \& Stewart, 2015), which poses clear agility-related challenges for 
organizations. Due to their digital nature, these challenges should be accounted for in IT governance. Failure to timely sense environmental change and respond readily can be detrimental for organizations (Overby, Bharadwaj, \& Sambamurthy, 2006). The VSM is particularly useful for systems that are operating in highly uncertain environments (Herring \& Kaplan, 2001). The five necessary and sufficient (sub)systems are interconnected through communication channels, which provides the viable system as a whole with the capacity of adaptation (Beer, 1979). The fact that a system is dealing with a quickly fluctuating environment is therefore also a focal reason for applying the VSM (Hobbs \& Scheepers, 2009b).

Finally, the VSM provides rigorous theory grounded in (management) cybernetics. Cybernetics is a grand theory that can provide a useful high-level way of thinking about many issues in IS research (Gregor, 2006; Richter \& Basten, 2014). As cybernetics is the science of control, and IT governance is concerned with control over (current and future) digital assets, cybernetics has been put forward as a suitable candidate theory for IT governance. This implies the applicability of the VSM for studying IT governance (Lewis \& Millar, 2009; Peppard, 2005; Skeivys, 2016).

\subsubsection{Theoretical Parallels Between the VSM and IT Governance}

Table 2 provides theoretical parallels between the underlying concepts, (sub)systems or functions, and communication channels or variety loops of the VSM (viz. Table 1) and IT governance.

Table 2. Theoretical parallels between the VSM and IT governance

\begin{tabular}{|c|l|}
\hline \multicolumn{2}{|c|}{ VSM underlying concepts and the relevance to IT governance } \\
\hline \multirow{3}{*}{ Viability } & $\begin{array}{l}\text { The purpose of IT governance is creating and preserving IT business value } \\
\text { (Weill \& Ross, 2004). An IT governance system is viable when it continues to } \\
\text { achieve this purpose. This is accomplished through leveraging digital assets } \\
\text { and activities, and controlling them. }\end{array}$ \\
\hline (Requisite) variety & $\begin{array}{l}\text { The contemporary business environment is characterized by digital disruptions } \\
\text { and digital transformations (Valentine \& Stewart, 2013), which are major } \\
\text { variety/complexity sources for organizations. Potential threats and } \\
\text { opportunities in such a turbulent business environment need to be detected, and } \\
\text { readily responded to (Overby et al., 2006). IT governance needs to have } \\
\text { sufficient variety to control the digital assets and activities in response to these } \\
\text { external disturbances, so that requisite variety can be established and viability } \\
\text { is ensured. }\end{array}$ \\
\hline
\end{tabular}




\begin{tabular}{|c|c|}
\hline Recursivity & $\begin{array}{l}\text { Controlling digital assets and activities should be established at different levels } \\
\text { of granularity (De Haes \& Van Grembergen, 2015; Prasad et al., 2012). For } \\
\text { instance, at the inter-organizational level, at the corporate level, at the business } \\
\text { domain-level, at the project level, at the project task-level, etc. Starting from } \\
\text { (corporate-level) IT governance, lower-level recursions will gradually flow } \\
\text { into IT management (Peterson, 2004b). }\end{array}$ \\
\hline Transduction & $\begin{array}{l}\text { Having a shared language is crucial to improve shared understanding between } \\
\text { business and IT stakeholders (Preston \& Karahanna, 2009). This reduces } \\
\text { possible distortion in communication between different stakeholders } \\
\text { (Hoverstadt, 2010). }\end{array}$ \\
\hline \multicolumn{2}{|r|}{ VSM (sub)systems or functions and the relevance to IT governance } \\
\hline System 1 & $\begin{array}{l}\text { To meet its purpose of creating and preserving IT business value, IT } \\
\text { governance leverages digital assets and activities (i.e. IT operations, IT projects } \\
\text { etc.) in a controlled way (ISO/IEC, 2008; Weill \& Ross, 2004). These assets } \\
\text { and activities therefore represent the reason for existence of the IT governance } \\
\text { system. }\end{array}$ \\
\hline System 2 & $\begin{array}{l}\text { This represents the coordination between, and within, the digital assets and } \\
\text { activities. As standards are often used as coordination mechanisms } \\
\text { (Hoverstadt, 2010), self-regulation could for instance be achieved by using IT- } \\
\text { related standards or frameworks (e.g. PRINCE2 for project management or } \\
\text { ITIL for IT service management). }\end{array}$ \\
\hline System 3 & $\begin{array}{l}\text { Responsible for ensuring that the total set of digital assets and activities (i.e. } \\
\text { System 1) is a coherent and cohesive whole. Specific responsibilities include } \\
\text { IT resource management, IT performance measurement, and enforcing IT- } \\
\text { related policies (cfr. "command axis"). }\end{array}$ \\
\hline System $3^{*}$ & IT-related audits (e.g. IT project audit, IT security audit etc.) \\
\hline System 4 & $\begin{array}{l}\text { Responsible for sensing opportunities and threats in the environment that are } \\
\text { IT-related or in which IT could play a role (e.g. keeping up with emerging } \\
\text { technologies, scanning for digital transformations in the industry etc.) (Overby } \\
\text { et al., 2006). This is considered an important organizational capability that } \\
\text { enables agility (Sambamurthy, Bharadwaj, \& Grover, 2003). System } 4 \text { is also } \\
\text { responsible for communicating with the environment about how the } \\
\text { organization is governing and/or leveraging its digital assets, i.e. IT governance } \\
\text { transparency (De Haes, Huygh, \& Joshi, 2017; Joshi, Bollen, \& Hassink, } \\
\text { 2013). }\end{array}$ \\
\hline System 5 & $\begin{array}{l}\text { As IT governance is a focus area of corporate governance, the board of } \\
\text { directors should be (directly or indirectly) involved (Andriole, 2009; Nolan \& } \\
\text { McFarlan, 2005). Even more so, board involvement in IT governance is vital } \\
\text { for ensuring its effectiveness (Turel \& Bart, 2014). Overviewing the S3-S4 } \\
\text { variety loop, system } 5 \text { (i.e. the board itself or a structure directly reporting to } \\
\text { it) assures that the IT-related strategic decisions will contribute to the } \\
\text { achievement of organizational objectives. }\end{array}$ \\
\hline \multicolumn{2}{|c|}{ VSM communication channels or variety loops and the relevance to IT governance } \\
\hline $\begin{array}{l}\text { Communication } \\
\text { with the } \\
\text { environment }\end{array}$ & $\begin{array}{l}\text { Communication with the environment happens in two ways: (1) with the total } \\
\text { environment through system } 4 \text { (viz. IT governance transparency) and (2) with } \\
\text { the embedded environments through system } 1 \text { (e.g. with software vendors or } \\
\text { service providers). }\end{array}$ \\
\hline
\end{tabular}




\begin{tabular}{|c|l|}
\hline Command axis & $\begin{array}{l}\text { The combination of IT resource management, IT performance measurement, } \\
\text { and enforcing IT-related policies (viz. responsibilities of system 3). }\end{array}$ \\
\hline Algedonic channel & $\begin{array}{l}\text { Used to raise alarm in the case of severe IT-related incidents (e.g. security } \\
\text { breach). }\end{array}$ \\
\hline S3 - S4 homeostat & $\begin{array}{l}\text { Considering the current state of affairs (system 3) and the possible future states } \\
\text { (system 4), this variety loop concerns IT strategic decision-making. It is } \\
\text { overviewed by system 5, to ensure that the outcomes of this process (e.g. IT } \\
\text { strategic plan) are in line with the overall direction, values, and purpose of the } \\
\text { system (e.g. business strategic plan). }\end{array}$ \\
\hline
\end{tabular}

Figure 2 shows how the essence of a viable system (viz. Figure 1) applies to IT governance. Digital disruption is an example of an environmental variety source that is relevant to IT governance (Valentine \& Stewart, 2013). Through leveraging (circle) and controlling (square) digital assets and activities, the viable system seeks to establish requisite variety. Only when requisite variety is maintained, the IT governance system will remain viable (i.e. continue to achieve its purpose of creating and preserving IT business value). The dashed connection between IT governance and the environment represents the system 4 functions of IT governance transparency (Joshi et al., 2013) and sensing environmental change (Overby et al., 2006).

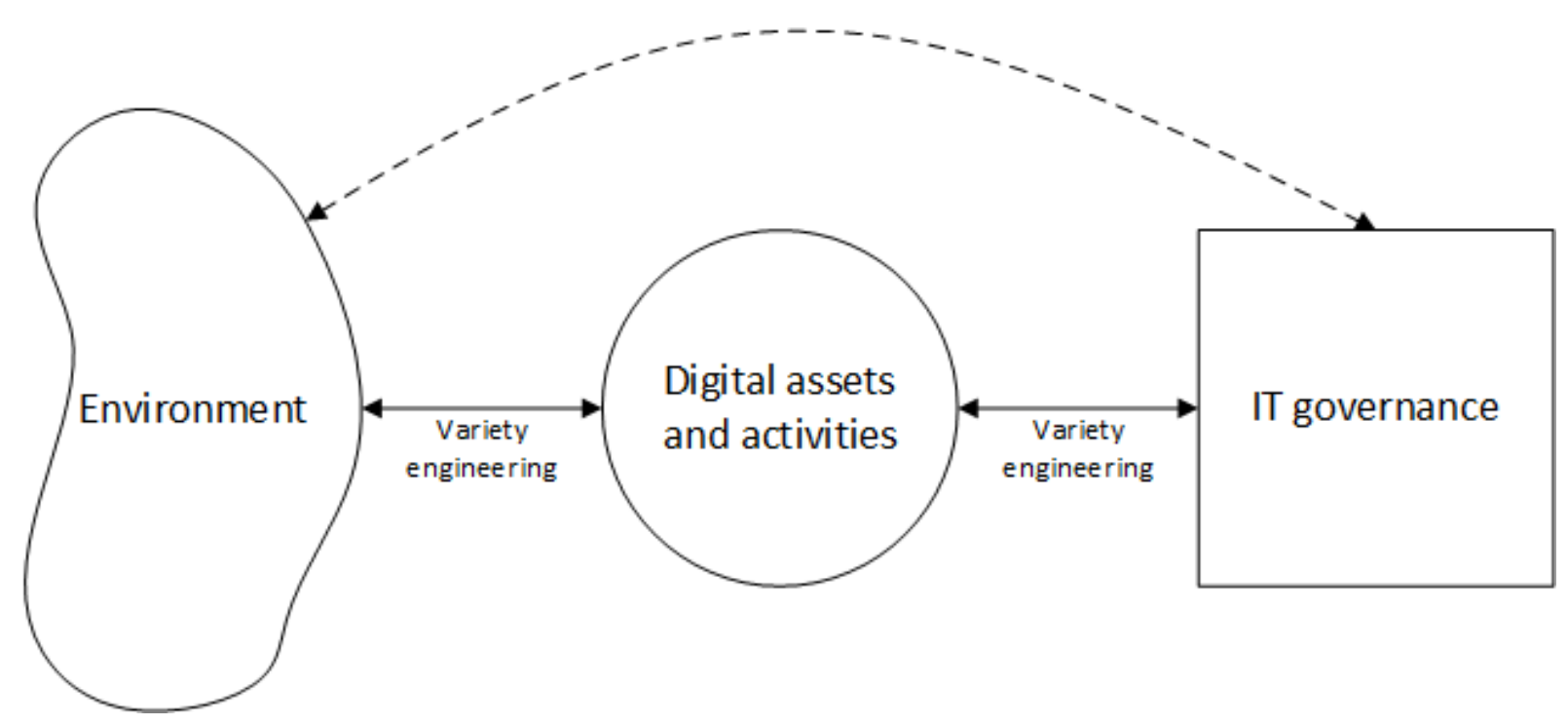

Figure 2. Establishing requisite variety between the environment, digital assets and activities, and IT governance (based on Beer (1985)) 
Based on the identified theoretical parallels, the following VSM-based principles are derived that explain why IT governance can continue to achieve its purpose of creating and preserving IT business value.

- The IT governance system timely senses environmental change, and responds readily by reconfiguring the digital assets and activities.

- The IT governance system is dynamic in response to the reconfiguration of digital assets and activities.

These principles are grounded in the law of requisite variety. The first principle ensures sensing changes in environmental variety and responding by changing the variety of what is controlled. The second principle is aimed at changing the variety of the controller as a response to the changes in the variety of what is controlled. The goal of this process of variety engineering is establishing requisite variety so that the viability of the system is ensured.

Building on these fundamentals of management cybernetics, IT governance will have the capacity to self-organize through variety engineering, thereby ensuring viability, if the five necessary and sufficient interconnected VSM subsystems (i.e. systems 1 through 5) are accounted for in the IT governance arrangement. A viable IT governance system continues to achieve its purpose of creating and preserving IT business value.

Therefore, the following VSM-based theoretical proposition is derived for IT governance:

The five necessary and sufficient interconnected VSM subsystems (i.e. systems 1 through 5) need to be accounted for in an IT governance arrangement to enable the continuation of achieving its purpose of creating and preserving IT business value.

\section{RESEARCH PHILOSOPHY AND APPROACH}

The viable system view can be classified as a 'functionalist' systems thinking approach, for which the underpinning is that "systems appear as objective aspects of a reality independent of us as observers" (Jackson, 2000, p. 107). This means that the systems are treated as real world ontological entities 
(Hoverstadt, 2010). However, it is entirely possible to take a more 'interpretivist' position with the VSM (Preece, Shaw, \& Hayashi, 2013), where the underpinning is that “[...] multiple perceptions of reality exist, and sometimes come into conflict” (Jackson, 2000, p. 211). In this view, systems are treated as epistemological constructs rather than ontological entities (Hoverstadt, 2010). When using the VSM as a lens to describe, diagnose, or design IT governance; a more interpretivist position is taken (Peppard, 2005).

The empirical part of this article employs case study research to demonstrate how the VSM can be used as a lens to describe and diagnose IT governance from a practical perspective. The case study method has been found very useful in order to observe day-to-day routines performed by organizations (Pykäläinen, Yang, \& Fang, 2009; Yin, 2014) and is applicable if a more extensive and in-depth study of the phenomenon of interest is required (Yin, 2014).

The linear but iterative case study research process (and related guidelines) by Yin (2014) was used over the course of this research. It consists of the following stages:

- The 'plan' stage is mainly about identifying the relevant situation for doing case study research, as opposed to other research methods. This was briefly discussed above.

- The 'design stage' is about defining the unit of analysis of the case(s) to be studied, the development of theory and propositions to guide the case study research and to enable generalization of the findings by means of analytic generalization, the selection of a specific case study design (e.g. single or multiple-case design), and testing the proposed design against the four relevant dimensions of research quality. The unit of analysis in this study is the IT governance system. The theoretical framework that guides the research is the VSM, which is grounded in (management) cybernetics. A single case study design will be used. Research quality was safeguarded through multiple strategies: (1) maintaining a chain of evidence and allowing key interviewees to review the research report to ensure construct validity; (2) making use of the VSM as an established theoretical lens and using thick case description to ensure internal validity; (3) the development of an interview protocol, recording the interviews, and using multiple viewpoints (both business and IT), as well as data 
triangulation (interviews and company documents) to ensure reliability. External validity cannot be ensured without a multiple case design, considering multiple relevant contingency factors.

- The 'prepare' stage is mainly about developing a case study protocol, screening and selecting final cases, and conducting a pilot case study. Additionally, it is important that the researcher conducting the case study research has the appropriate skills (i.e. the ability to ask good questions, to be a good listener, to stay adaptive, to have a firm grasp on the issues being studies, and to avoid biases and conduct the research ethically).

- The 'collect' stage is about actually collecting case study evidence. Special care should be given to four data collection principles: data triangulation, constructing a case study database, maintaining a chain of evidence, and exercising care when using data from electronic sources. During our case study, data was triangulated by means of multiple semi-structured interviews, as well as internal company documents (e.g. meeting agendas, internal company presentations etc.)

- The 'analyze' stage is about using the collected evidence to produce empirically based findings. During this research, the collected data was analysed using qualitative content analysis by employing the VSM as a theoretical lens, with the goal of describing and diagnosing the IT governance system. Special attention was given to (1) components of the VSM that could not be found at the case company, and (2) IT governance mechanisms found at the case company that could not be mapped to the VSM. At the end of the analysis stage, the case description was reviewed and approved by the main interviewee, the $\mathrm{CIO}$, to ensure correct representation of the facts.

- Finally, the process ends with the 'share' stage, which is about sharing the conclusions of the case study.

Each interview was conducted in a semi-structured fashion. All interviews were recorded and fully transcribed. The CIO was the sponsor of this case study at the organization, with whom four meetings were planned. Snowball sampling of other relevant interviewees was achieved through the CIO. The goal was to include key stakeholders in the IT governance system, and to get a balanced perspective between the business and IT. The three other interviewees were only interviewed once. Each interview 
lasted between 45 and 90 minutes. Contradictory evidence in different interviews was verified with other stakeholders and ultimately with the CIO.

\section{A VIABLE SYSTEM'S VIEW ON ACERTA'S IT GOVERNANCE}

\subsection{Introducing Acerta and their IT Governance System}

Acerta is an HR services provider in Belgium that specializes in advice, computerization and processing of administrative processes for payroll, social security, child benefits and branch formalities. Therefore, Acerta's customers are enterprises of all sizes, and self-employed workers. Nearly $30 \%$ of all selfemployed workers in Belgium (ca. 270,000) are affiliated to Acerta for the social insurance fund. More than one out of four Belgian private sector organizations (ca. 50,000) uses Acerta's payroll processing services. Acerta is also responsible for the payroll calculation of more than one out of three workers within the Belgian public sector (ca. 220,000), both statutory and contract workers. Nearly 13\% of people receiving social benefits in Belgium do so via Acerta (ca. 140,000). Acerta has more than 1,300 employees spread across 38 offices in Belgium. The firm had a turnover of just over 160 million euros in 2015. Acerta is not a publicly listed company. Instead, it is owned by two shareholders who each own 50\% of the shares. In 2015, Acerta’s total IT budget was 49 million euros. For 2016, it was also set to be 48 million euros and therefore relatively constant. The tendency since 2012 is that Acerta's IT budget lies between 40 and 50 million euros, as this can be supported by their contemporary cost structure. In 2015, ca. 70\% of the IT budget was used to run the business (i.e. "to keep the lights on”, including operational costs and small maintenance projects to maintain the existing portfolio), while ca. $30 \%$ was used to change the business (i.e. projects for "new IT”, both smaller and strategic). Again, the numbers for 2016 are approximately the same. In terms of IT costs, ca. 30\% of Acerta's total expenses are ITrelated. Therefore, Acerta is very dependent on IT, especially on highly reliable operating systems. Acerta does however not claim to be a front-runner in the continuous application of emerging technologies.

Acerta developed its own IT governance model, Bita+, standing for "business/IT alignment plus". This model is largely developed under supervision of the current CIO, who joined Acerta in 2012. Bita+ is 
extensively based on his prior experience as CIO of a large Belgian bank. The preparation year for the Bita+ implementation at Acerta was 2013, while the actual implementation started in 2014 and lasted for about 6 months. This fast implementation time can be attributed to the fact that the new CIO already had the blueprint for the Bita+ model developed at the large bank, which was then scaled to Acerta (being approximately $1 / 10^{\text {th }}$ the scale of the bank). The Bita + model is not specifically based on a good practices framework for the enterprise governance and management of IT (e.g. COBIT 5). Nevertheless, the CIO states that: "When you would map our processes to the COBIT 5 processes, you would find that approximately $80 \%$ of what is contained in COBIT 5 can also be found at Acerta."

The main trigger for Acerta to implement the Bita+ IT governance model traces back to the preparation stages of a major IT project that was deemed to be critical for the company ( $>70$ million euros). At that point, the IT governance arrangements available were deemed to be vastly insufficient to deal with the complexity of the project and the to-be state of Acerta's IT. The appointment of the new CIO in 2012 can also be identified as a trigger event. Therefore, the CIO acknowledges that the design and implementation of Acerta's contemporary IT governance system was reactive rather than proactive. The prior IT governance system at Acerta was referred to as Bita, and essentially consisted of a centralized change advisory board (CAB) as described in ITIL (i.e. a good practices-framework for IT service management). The CAB consisted of four executive committee members who discussed everything ITrelated and made all the decisions, resulting in very centralized IT decision-making.

Over the course of this case study, the following stakeholders were interviewed at Acerta (Table 3).

Table 3. Interviewees and their role at the company

\begin{tabular}{|l|l|}
\hline Interviewee/Stakeholder & \multicolumn{1}{|c|}{ Role } \\
\hline $\begin{array}{l}\text { The chief information } \\
\text { officer (CIO) }\end{array}$ & $\begin{array}{l}\text { This stakeholder is ultimately responsible for IT governance. He joined } \\
\text { the company in 2012, during a time when it was acknowledged that } \\
\text { Acerta's IT governance needed to change. He brought a lot of prior } \\
\text { experience as CIO to the table, which he used extensively for the } \\
\text { challenge of re-designing the IT governance. The CIO has a seat at the } \\
\text { executive committee and has a direct reporting line to the supervisory } \\
\text { board. He also has a seat in the major IT governance structures. }\end{array}$ \\
\hline $\begin{array}{l}\text { The IT governance } \\
\text { manager }\end{array}$ & $\begin{array}{l}\text { This stakeholder watches over the IT governance processes. } \\
\text { Additionally, he is the application manager for the IT governance-related } \\
\text { tools (e.g. the IT governance intranet section). The clear majority (80 to }\end{array}$ \\
\hline
\end{tabular}




\begin{tabular}{|l|l|}
\hline & $\begin{array}{l}\text { 90 \%) of his time goes in the preparation and follow-up of the meetings } \\
\text { of the IT governance structures. During these meetings, he ensures that } \\
\text { the difficult questions are asked (e.g. related to timing and budget), to } \\
\text { ensure the proper working and relevance of the IT governance structures } \\
\text { and their meetings. He is the single point of contact within the company } \\
\text { for questions regarding IT governance, thereby giving advice on the } \\
\text { application of IT governance principles when needed. The IT } \\
\text { governance manager belongs to the business management \& support } \\
\text { business domain, and is viewed as a business function. This was done } \\
\text { specifically to ensure that IT governance would be viewed as a business } \\
\text { issue, i.e. that the business should be in control. }\end{array}$ \\
\hline $\begin{array}{l}\text { The managing director of } \\
\text { the "payroll services" } \\
\text { business domain }\end{array}$ & $\begin{array}{l}\text { This stakeholder is ultimately responsible for the budget of the business } \\
\text { domain that traditionally has the highest budget available for IT projects. } \\
\text { As head of payroll services, she has the final decision-making authority } \\
\text { in portfolio management \& prioritization of this business domain. Like } \\
\text { the other managing directors, she has a seat at the executive committee, } \\
\text { where she is directly involved with corporate IT strategic planning and } \\
\text { budgeting. }\end{array}$ \\
\hline $\begin{array}{l}\text { The enterprise architect } \\
\text { of the two internal service } \\
\text { domains ("Acerta HRM" } \\
\text { and "ICT support”) and } \\
\text { the "business } \\
\text { management \& support" } \\
\text { domain }\end{array}$ & $\begin{array}{l}\text { This stakeholder works together with the other enterprise architects and } \\
\text { the CIO, under the form of the enterprise architecture forum (EAF), in } \\
\text { determining the long-term IT vision, thereby also supporting the } \\
\text { development of the long-term (financial) plans. Evaluating emerging } \\
\text { technologies and their application opportunities is therefore one of his } \\
\text { key tasks. Enterprise architects are positioned as bridge functions } \\
\text { between business and IT at Acerta. }\end{array}$ \\
\hline
\end{tabular}

\subsection{Acerta's IT governance as seen through the VSM}

\subsubsection{Governing and Managing IT at the Corporate Level}

\section{System 1}

Acerta recognizes two main components of digital assets and activities: IT projects (referred to as change IT) and IT operations (referred to as run IT). At Acerta, these assets and activities are distributed following the business domain architecture. Acerta recognizes seven distinct business domains (Figure 3). The first business domain is customer approach, which is mainly concerned with distribution. Second, three product factories are recognized as separate business domains: starters \& independents, payroll services, and $H R$ consult. Third, the business management \& support domain focuses on Acerta's financials, intelligence, profitability and enterprise supporting functions. Finally, Acerta HRM and ICT support are internal service domains focusing on resources and assets. 


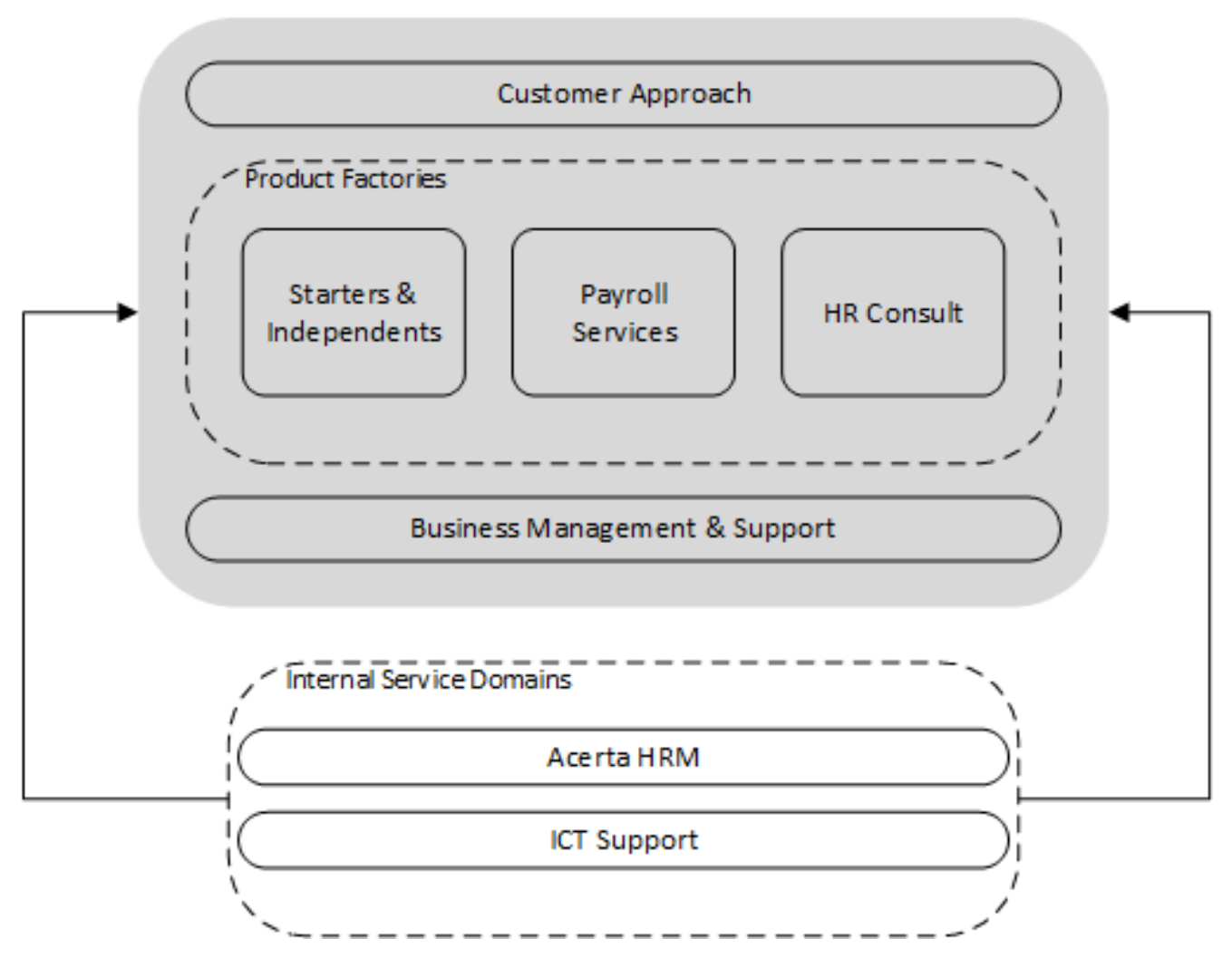

Figure 3. Business Domain Architecture at Acerta

In terms of total IT budget, the ICT support business domain is the largest. This budget is used for ensuring the run IT of all business domains, e.g. by investing in server infrastructure (change IT of the ICT support business domain) and keep them running (run IT of the ICT support business domain). The clear majority of ICT support's IT budget (ca. 75\%) is used for covering the operational costs (e.g. electricity bill of the servers). Acerta does not make use of activity-based costing procedures to assign the operational costs (i.e. the costs of run IT) to the relevant other business domains, they are all ultimately covered by the IT budget of the ICT support domain. The other business domains are therefore only carrying the costs of the change IT initiatives.

Of the remaining business domains, payroll services traditionally has the highest IT budget (with 17.3 million euros in 2016 about four times larger than starters \& independents, which is the next-largest IT budget). The IT budgets (in millions of euros) of the seven business domains for 2016 are presented in Figure 4. The part of the budget that is allocated to run IT consists of operational costs and small maintenance projects to maintain the existing assets (i.e. "to keep the lights on”), while change IT consists of projects for “new IT”, both smaller and strategic. 
An important contemporary example of a project in the change IT portfolio is the new wages engine project, belonging to the payroll services business domain. This project is worth over 20 million euros and is directly related to the core business activities of Acerta, making it a very critical strategic IT project. New wages engine was launched based on an underlying technology that will significantly increase processing efficiency, which was deemed necessary to stay competitive in the market. The project started in Q1 2016 and is scheduled to be finished by the end of 2017. The internal financial ERP system is an example of run IT. This application is owned by the business management \& support domain and provides internal financial transparency to all relevant stakeholders.

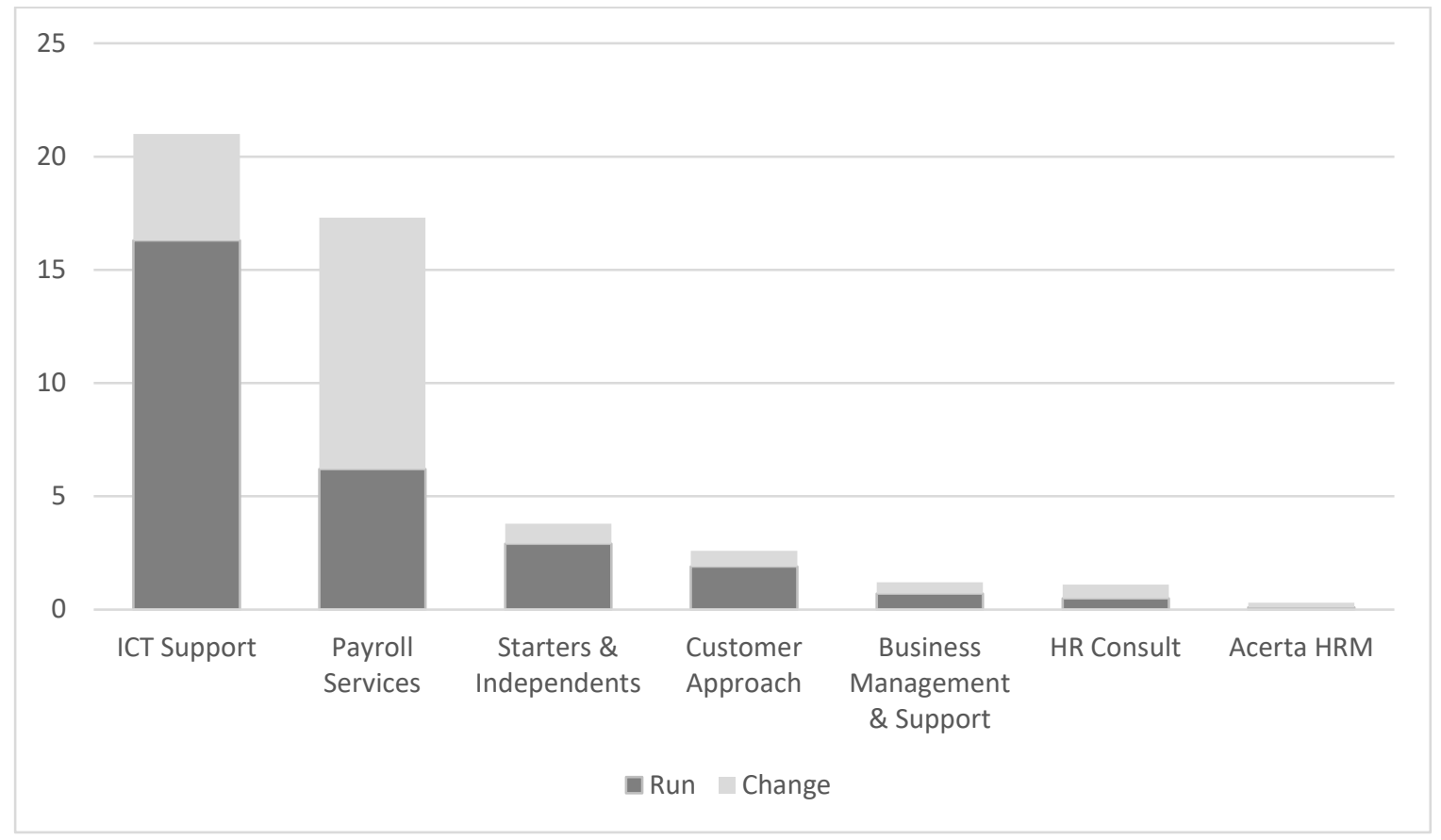

Figure 4. IT Budget for 2016 (in millions of euros)

Each of the seven business domains have a dedicated activity steering committee (ASC), consisting of the corporate $\mathrm{CIO}$, the business domain managing director, the business domain enterprise architect(s), and the corporate IT governance manager; which is granted a specific and autonomous IT budget by the executive committee as decided in the long term financial plan (which is negotiated at the executive committee and ultimately approved by the supervisory board). A business domain ASC is responsible for the digital assets and activities of that business domain. Every IT project (change IT) and IT application (run IT) is owned by a single business domain. The CIO specifically states that the goal of 
this business domain architecture, and the clustering of digital assets and activities over these business domains, is to enable local autonomy. The managing director of the payroll services business domain acknowledges the improvement in local autonomy compared to the previous situation in which IT budgets and IT projects were not appointed to the business domains. Now, the business feels more in control of IT-related budgets and running IT projects.

The yearly planning for an ASC is presented in Figure 5, divided over the four quarterly meetings. In the past, ASC meetings would only occur on a yearly basis. Under Bita+, the decision was made to let an ASC meet on a quarterly basis, to improve its decision-making frequency. The managing director of the payroll services business domain states: "The new frequency of ASC meetings is better. We now understand that discussing the budgeting within a business domain only once each year slowed us down. The frequency of ASC meetings should not be increased further however, as we have structures directly below it that are covering the more operational aspects." Each ASC meeting starts with a follow-up of the previous quarter, as well as a discussion regarding corrections for the next two quarters.
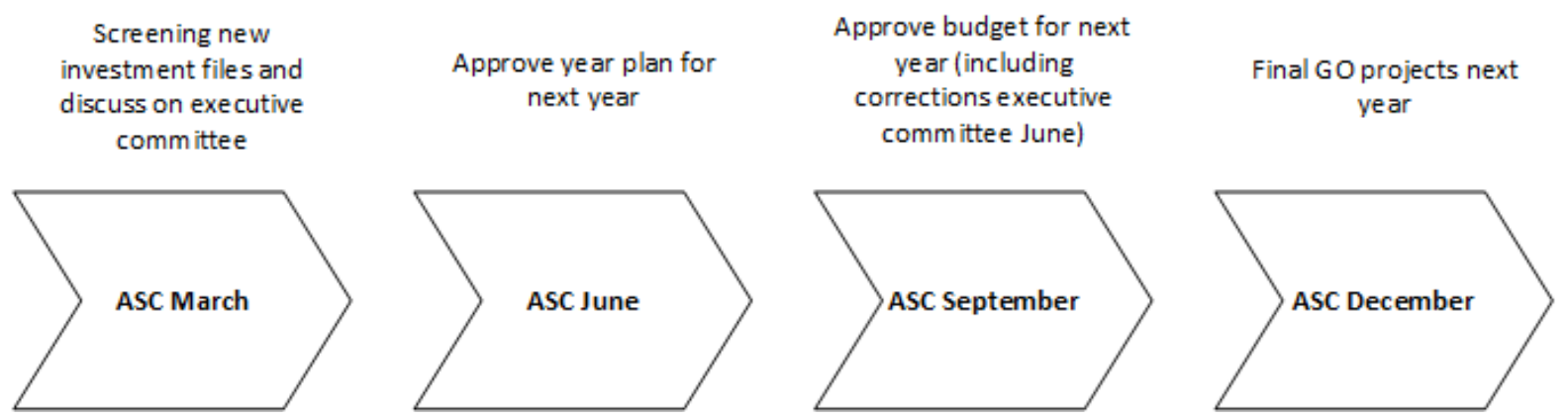

Figure 5. ASC yearly planning (quarterly meetings)

Acerta's IT governance system enables the fast detection of a crisis. For instance, the IT-related potential incidents at Acerta are classified from low to very high per impact. When an incident that is classified as very high occurs, the executive committee receives an e-mail from the service management system in real-time. The managing director of the payroll services business domain, who is a member of the executive committee, says: "the business implications of the incident are very often clear when reading this automated mail. However, it requires a certain skill to see the link between cause and effect. Nevertheless, I can always immediately gauge the seriousness of the situation based on these emails." 
Additionally, as the CIO also has a seat on the executive committee, while at the same time being a member of all the business domains' ASCs (and being the managing director of the ICT support business domain), it is also ensured that IT-related issues can be brought easily upwards.

\section{System 2}

With its business domain architecture (Figure 3), Acerta aimed to minimize the number of business domains, while at the same time maximizing internal consistency of each domain. Accordingly, this minimizes the number of potential links between business domains, which is a large determining factor in the complexity to deal with, as the possible number of connections between domains (and therefore the complexity) increases exponentially with each extra business domain.

Albeit that there formally is no overlap between the different business domains' digital assets and activities, Acerta recognizes that there are links between the different business domains. This is a direct consequence of appointing the ownership of every IT project (and the resulting run IT) to a single business domain, while these projects do not only influence the business domain that has the ownership. The managing director of payroll services explains: "the projects are always appointed to a single business domain, but a given project does not necessarily influence only a single business domain. This results in multiple business domain intersections, which is sometimes a little difficult."

For instance, it is possible that one domain is requested to do something for another domain in the realm of a running IT project. A formal agreement between both domains is then made by their respective ASC's to coordinate the intersection and the relevant IT budget is used to compensate the efforts. This formal agreement also contains performance targets (e.g. the time by which the project should be in the testing phase). A recent example of this is related to the strategic project new wages engine. While this project is ultimately assigned to the payroll services business domain, the finance department, as part of the business management \& support domain, is responsible for the service catalog and billing parts of this project. For this reason, they are in control of this specific subproject (for a total of 906,606 euros). Hence, this is an example of an intersection between the payroll services and the business management \& support domain, at the level of a single project. 
An important coordination structure is the Enterprise Architecture Forum (EAF), which is composed of the enterprise architects of all the business domains and chaired by the CIO. The EAF typically meets every two weeks, but since Acerta is currently in the process of undergoing some major strategic IT changes, the frequency of EAF meetings has been increased to every week. The CIO states: "The enterprise architects essentially have two roles: first, they are responsible for the consistency within their business domain; and second, when they are sitting together under the form of the EAF, they are responsible for the consistency of the whole.” The enterprise architect is a new role that was introduced with the Bita+ system. Not every business domain has a single dedicated enterprise architect. For instance, the payroll services business domain has two dedicated enterprise architects, as the strategic IT budget of this business domain is considerably larger than the other business domains. On the other hand, the internal service domains (viz. Acerta HRM and ICT support) share an enterprise architect. This appointing of business domains to enterprise architects was done to ensure that each enterprise architect function would be full-time.

By means of the EAF, synergies between digital assets and activities are sought at the corporate level. For instance, if a new project is requested by a certain business domain, the application opportunities and implications for other business domains is analyzed at the EAF. The managing director of the payroll services business domain acknowledges the importance of the EAF when it comes to ensuring corporate IT consistency. She states: "In the previous there was no EAF. Back then it was not unthinkable that two different business domains would initiate essentially the same project apart from each other, but for meeting two different business needs. Now, the EAF ensures that the single project meets both business needs, thereby preventing redundancy.” The enterprise architects are viewed by the business as important bridge functions between business and IT. They possess technical capabilities as well as the ability to talk with the business in a language they understand. The EAF ensures that the visions of all the enterprise architects remain on the same track. This is very important to safeguard the strategic goals of Acerta. Another important coordination function of the EAF is change management. In close collaboration with business process owners, the enterprise architects are gauging the potential effects of a new system on the internal stakeholders. A mechanism that is frequently used are pit-stop 
sessions, where impacted stakeholders are invited with the goal to explain them the changes and get them involved with the new systems early on.

Acerta maintains an IT governance section on their intranet, containing information about Bita+. Relevant internal stakeholders can for instance view the portfolios of digital assets and activities and the investment decisions that are made. This also serves as a coordination mechanism, as employees are hereby informed about the way in which Acerta is governing its digital assets and activities, with the aim of improving internal transparency and coordination of internal actions. Acerta is also developing an IT for dummies section on its intranet, which should ensure that stakeholders understand the importance of IT for Acerta and the basics of the governance and management of IT at their company. Finally, Acerta employs several IT-related standards, facilitating a standardized way of working: e.g. ITIL for IT service management (“run”) and PRINCE2 for IT project management (“change”).

\section{System 3 and System 3*}

The (IT) budgets for the ASC's are granted by the executive committee. At this level, a yearly discussion is devoted to the overall IT budget to safeguard consistency with the long term financial plan and to formally approve the investment portfolio. This is a two-way bargaining process, as the managing directors of all the business domains have a seat in the executive committee to participate in these discussions. The ASCs are then held accountable for the budgets they are granted. Within the finance department (belonging to business management \& support), each business domain (and therefore each ASC) is appointed a financial controller that is responsible for monitoring the usage of these budgets (i.e. performance measurement). Monthly, the ASC budget consumption is then reported back to the executive committee.

Acerta has a dedicated risk committee that is chaired by the CIO and of which approximately half of the executive committee is a member. This committee focuses on business risks as well as IT-related risks. The CIO was appointed as chair of this committee, as it was acknowledged that IT-related risks are a major source of risks for the company. This committee is directly reporting to the executive committee. To enable useful discussions of these issues, the business and IT-related risks are presented by means of a risk map. This risk map is developed as a mutual effort between business and IT (i.e. managing 
directors and the CIO) and classifies all the identified risks on two dimensions: likelihood of happening and the impact when it happens. Logically, the goal is to focus first on the risks that have a high chance of happening and a high potential impact when they happen. For instance, cyber risk: hacking is an example of an item on the most recent risk map that was classified as belonging to the highest potential impact category and the highest likelihood category.

Additionally, the most important evolutions on the risk map are separately discussed using four risk categories: increasers, decreasers, new, and gone. The responsibilities of the risk committee are classifying these risks, as well as creating and maintaining the risk policy and the risk management strategy. The progress in the business domains of the proposed risk mitigating actions is also followed up by this committee. When communicating the IT-related risks to the executive committee, special attention is given to make sure that the business implications are very clear. This is of course already safeguarded by the fact that business and IT stakeholders are both involved in developing the risk map and classifying the risks. The risk committee is responsible for enforcing certain risk and security-related policies. For instance, there are hard IT security-related policies (e.g. password policies and policies of logical access security), which are communicated to the employees using the intranet. These policies are also audited accordingly. Failure to comply with these policies is considered a labor offense.

At Acerta, external IT auditing is formalized by means of a contract with a third-party IT auditing company, who provides full coverage (e.g. security audit, project audit, method audit, etc.). Additionally, Acerta continuously monitors certain aspects at the operational level, especially related to the security of their networks. In cooperation with an external IT consultancy company, Acerta also organizes two times each year a real-life crisis simulation. The last edition of this test concerned a hacker who claimed having stolen confidential information from their servers about one of Acerta's largest customers. These crisis simulations provide an excellent way to gauge the as-is state of the responsiveness to such situations. Internally, the executive committee, via the financial controllers, can audit the budget consumption of each of the ASCs when deemed appropriate (i.e. by exception). In practice, this does almost never happen, because of the internal financial transparency provided by the financial ERP system. Monitoring by exception differs from the regular performance measurement in 
the sense that it is not exercised at regular intervals, but only when deemed appropriate by the executive committee.

\section{System 4}

At Acerta, scanning of emerging technologies is one of the responsibilities of the Enterprise Architecture Forum (EAF) (viz. composed of the four enterprise architects of the business domains and chaired by the CIO). However, it is acknowledged that Acerta is not continuously scanning its environment for strategic opportunities using emerging technologies, as the identity of Acerta's IT is more geared towards being highly operationally reliable instead of being a front-runner in the application of new technologies. Nevertheless, potential applications of emerging technologies are placed on the agenda at EAF meetings. Recent discussions regarding emerging technologies at the EAF were for instance about big data, internet of things, and in-memory technologies. The enterprise architect clarifies: "Discussing emerging technologies at the EAF is organized more or less ad-hoc. If I must put a frequency on it, I would say that these things are discussed 4 or 5 times a year at the EAF." The enterprise architects are facilitated in exercising their intelligence function. For instance, they are encouraged to attend Gartner workshops, they have access to Gartner reports (e.g. hype cycles), and they are also encouraged to pro-actively seek courses they would like to attend.

Acerta uses multiple channels to communicate with the stakeholders that influence and/or are influenced by its digital assets and activities. First, the annual report was used in the past to be transparent about certain IT-related matters. Nevertheless, the annual report never contained specific information about how Acerta was governing its IT. For the last two years, Acerta released a very brief annual report, containing only the most important company information. The CIO states: "For us, the annual report is a nice document when printed, but when we hand it out, people put it somewhere and then it just starts gathering dust. Nobody is really doing anything with that document." When it comes to communicating with its customers, several different channels are used. For instance, Acerta communicates their quality labels (e.g. ISAE3402 ${ }^{3}$ ) to their customers using e.g. commercial brochures. Customers can also be

\footnotetext{
${ }^{3}$ International Standard on Assurance Engagements (ISAE) No. 3402, Assurance Reports on Controls at a Service Organization.
} 
actively involved. For instance, a very important customer of Acerta is allowed to audit their IT-related matters on regular intervals.

To ensure self-awareness, a central spreadsheet of the corporate digital assets and activities is maintained by the EAF. This is of course a requirement before potential new projects can be proposed. Without this information centralized, there would be a clear risk at redundancy. The EAF, in collaboration with ICT architects and business process owners, is also responsible for modelling Acerta's enterprise architecture. This is guided by an EA framework based on Capgemini's Integrated Architecture Framework (IAF). Multiple types of stakeholders are involved in EA modelling, as the framework is built around four quadrants: business architecture, ICT architecture, business design, and ICT design. The enterprise architect explains: "We do use the EA models when gauging the applicability of new ideas, however, these models are not maintained on a continuous basis. With each major IT project, however, there is a boost to get them up-to-date." Related to the self-awareness of an IT governance system, the as-is maturity of the IT governance practices also comes to mind. At Acerta, formal maturity assessments of IT governance practices are not conducted. The IT governance manager explains: "It is very difficult to formally assess the maturity of IT governance structures and processes. Nevertheless, you get a feeling of the maturity when attending meetings of IT governance structures.”

\section{System 5}

At Acerta, IT is considered to be a business enabler. The managing director of the payroll services business domain acknowledges an improvement from the old Bita to the new Bita+ arrangement. She says: "IT is now regarded more as a business enabler. In the previous it was regarded more as a cost center. I think the establishment of the EAF was very important in changing the business' perception of IT. The enterprise architects are talking with the business in terms of application opportunities, which is a major improvement compared to the past." The establishment of the identity of IT starts with tone at the top. Board-level IT oversight is exercised for instance through the annual presentation of the IT strategy by the CIO to the supervisory board. The directors can then ask critical questions regarding the business implications of the IT strategy. Additionally, the CIO adds IT-related comments to the monthly performance reports that the supervisory board receives. Acerta's supervisory board contains IT 
expertise and experience. Specifically, it contains a member who owned and managed an IT company, as well as an independent director who has an IT audit and consultancy background. The CIO, wo is a member of the executive committee, stated that putting IT expertise and experience in the supervisory board was done on purpose, acknowledging the IT intensity of Acerta. Nevertheless, the CIO acknowledges that "when communicating with the board, it is very important to discuss the matters at hand in business language. If IT-related matters are discussed in technical jargon at board-level, the directors will not understand the issues and automatically think your proposal is bad."

As it is acknowledged that the major strategic IT project new wages engine is of such high importance to the business (and could even endanger the whole firm if things go awry), a specific sub-committee was established at supervisory board-level to monitor this project. Approximately half of the supervisory board is a member of this committee, as well as the CEO. The CIO directly reports to this committee on a quarterly basis. As this important project is also partially co-sourced in partnership with an external company, a steering committee was created that directly reports to this project monitoring committee with the goal of managing the relationship with the co-sourcing partner. Among the members of this steering committee are also representatives of this external partner.

\subsubsection{Governing and Managing IT at the Business Domain Level}

Within each business domain, the business domain managing director will act as system 5 ; setting the overall direction, values, and purpose of the business domain. In practice, this entails the translation of what is set at the corporate level for Acerta as a whole.

System 4 at the business domain level is operationalized by means of a structure called domain council. There is a unique domain council for each business domain. The enterprise architect of a given business domain is the chair of the domain council of that business domain. The domain council is responsible for conducting a pre-study about the problem statement that arises, and for discussing potential ITrelated solutions. The enterprise architect can propose ideas by himself, but this role also acts as a funnel for other stakeholders. For each idea, an idea-report will be drafted, which simply is a small one-pager that discusses a potential solution for a certain need. A standardized idea report template exists, containing three sections: as-is, to-be, and cost estimates. 
There can be multiple triggers for ideas that are discussed at the domain council: e.g. a modification required for legal/compliance reasons, a technological change, a business need, etc. At the domain council, the business is frequently involved in the discussions, to ensure business/IT alignment. For instance, relevant business process owners are always part of the domain council. The other members of a domain council can vary each meeting, depending on the ideas that are being discussed. In practice, more technically-oriented actors are often invited (e.g. ICT architects), who have technical expertise and/or experience relevant to the discussion. The frequency of domain council meetings depends on the specific business domain. For instance, the domain council of payroll services meets on a more regular basis than the domain council of HR consult, as the former domain is larger in terms of IT budget and consequently generally puts more ideas in the pipeline. When the domain council finished the pre-study for a given idea, it will be presented by the enterprise architect at the level of the business domain ASC.

Business cases are developed for potential projects. This process will be initiated first at the domain council, and external stakeholders can be asked to participate (e.g. financial controllers to check if the numbers are realistic). The contents of a business case tend to differ depending on the investment size at Acerta. For more important IT projects, business cases are developed in greater detail. A business case usually contains projected numbers for budget, timing, and scope. Additionally, the expected impact on business goals is discussed, which is also discussed more in depth if the project is more important. In a recent project that was about upgrading Acerta’s entire server infrastructure for instance, the goal was to increase operational efficiency by lowering operational costs. These projected numbers were also included in the business case. The enterprise architect is accountable for making the business case and bringing it to the ASC.

At the level of the system 3-system 4 feedback loop, portfolio management and prioritization happens within a business domain, overviewed by the managing director of that business domain. Within the budget that was assigned to each business domain's ASC (viz. by the executive committee at the corporate level), the prioritization of projects will indeed be done within the ASC, considering the input of the domain council (largely under the form of pre-studies). As the enterprise architect is also a member of the ASC, this feedback loop is indeed mutual between S4 and S3. A first draft project 
prioritization is always prepared by the enterprise architect for each ASC meeting. The managing director of payroll services stresses the importance of IT project prioritization, as "there are always more project ideas than there is budget in any given year." When a business case is too expensive to be carried by an ASC's assigned IT budget, but the project is of strategic importance, the business case can be brought to the executive committee, or even the supervisory board, via the business domain managing director. Recent examples of business cases that escalated this way are the new wages engine project (payroll services business domain), and a hardware upgrade of the entire server infrastructure (ICT support business domain).

The entire business domain ASC will act as system 3, responsible for resource bargaining, performance measurement, and enforcing policies within a given business domain. Within the constraints of the IT budget that is assigned to the business domain, resource bargaining exists for individual IT projects and maintenance envelopes. The consumption of these project and maintenance budgets is then also followed-up. The policies that are enforced can be business domain-specific or corporate policies flowing down directly from the corporate level (e.g. the IT security policies).

A business domain's available IT budget is divided in different chunks by its ASC (Figure 6). Specifically, each budget is divided over the following categories: break \& fix budget, functional maintenance, projects, and investments. The break \& fix budget is applied for system maintenance and solving small defects. The functional maintenance part of the budget is oriented at small enrichments, i.e. small enough that it will not be treated as a separate project (at Acerta the rule of smaller than 20 man days is maintained, where a man day is considered to cost 600 euros). Projects are then equal or larger than 20 man days and are part of the long term financial plan. Finally, investments are those projects that are big enough to require formal supervisory board approval. This last category is specifically aimed at meeting an important company objective or strategic goal and often leads to an increase in assigned IT budget, as investments often are projects of a magnitude that cannot be carried by a business domain's annual IT budget. The business cases for investments often represent a joint demand by multiple ASCs (as was the case with the recent server infrastructure upgrade). 


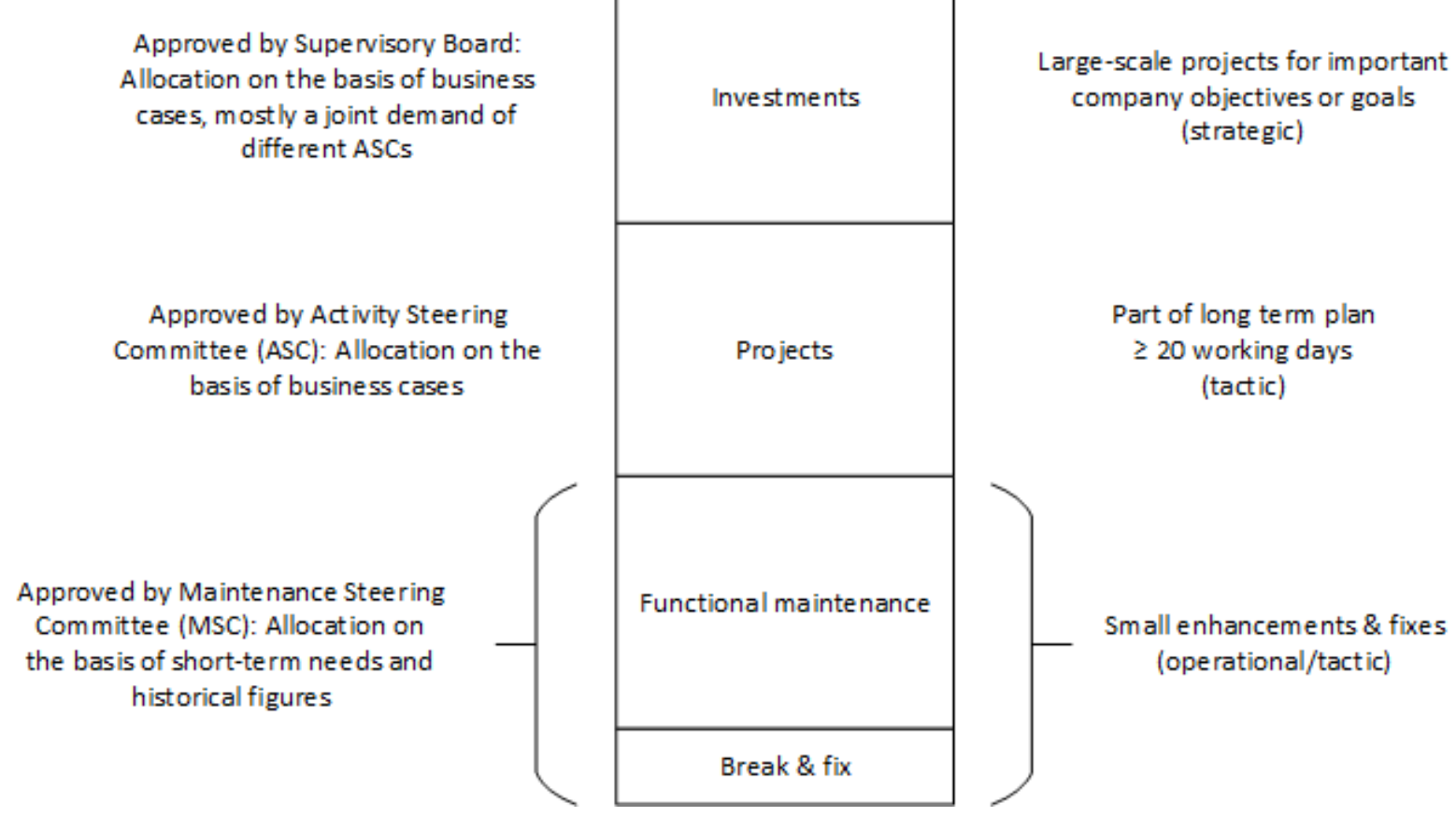

Figure 6. IT budget breakdown (note: the relative sizes of the parts do not reflect proportions of the IT budget)

Each ASC has a maintenance steering committee (MSC) directly below it. This structure meets once each month and is responsible for the break \& fix and the functional maintenance parts of the IT budget (i.e. responsible to "keep the lights on” within a business domain). The business domain application owner is selected as chairman of an MSC. The chairman is responsible for reporting back to the ASC (i.e. accountability reporting line/performance measurement). For instance, it is possible that an MSC runs out of budget because there are more issues than expected, e.g. due to the implementation of a certain change. The exact composition of an MSC is up to the chairman. It is however required that the IT governance practice of bringing relevant business and IT people together in the structures is followed (as is required for all IT governance structures at Acerta). Additionally, each business domain has a dedicated service meeting (ITIL-based). Acerta service desk reps (i.e. internal and external helpdesks), the application manager, and the team leader ICT form this structure and organize meetings to monitor and safeguard the service quality of Acerta's running IT.

When an idea is approved and prioritized within an ASC, the project can be launched. At this point, a PSC is put in place for project execution; i.e. a project workforce consisting of both business and IT people, chaired by a project leader and overviewed by the enterprise architect of the business domain 
that has ownership of the project. This structure generally meets every two weeks, but this can vary depending on the project or the phase the project is in. One of the PSC members is an ICT delivery manager, who is responsible for appointing the resources to the different project tasks. There is also a business change leader involved to also include the business perspective (e.g. to enable business process re-engineering). The PSC then also consists of ICT architects who are executing the project tasks. The enterprise architect has a monitoring/controlling function, and returns the feedback to the level of the ASC (i.e. accountability reporting line/performance measurement).

The business domain-level digital assets and activities are therefore divided into run IT and change IT, and managed accordingly by different structures (i.e. the MSC with the service meeting, and the PSCs for the projects). To coordinate between the change IT and run IT part of the business domain IT assets, release management for the coordination and smooth deployment of projects to production is implemented. This enables a smooth transitioning from projects to operations.

\section{DISCUSSION}

Acerta recently went through a major transformation of their IT governance system. Due to a very critical strategic IT project, it was acknowledged that the as-is state of Acerta's IT governance was insufficient. Because of that, the decision was made to drastically improve the IT governance system, and the new CIO was mandated in 2013 to lead this transformation. Both events (i.e. the enterprise-wide project and the new CIO) can therefore be identified as trigger events for Acerta's IT governance transformation. These events are also identified within the COBIT 5 framework, a leading goodpractices framework for the enterprise governance and management of IT, as events that often trigger a focus on IT governance (ISACA, 2012).

The preparation year of the implementation of the new IT governance arrangement, Bita+, was 2013, while the actual implementation started in 2014 and lasted for about 6 months. This fast implementation time suggests a low amount of change resistance. Indeed, the CIO acknowledged that during the preparation year of the Bita+ implementation, a lot of stakeholders got on board very quickly, largely because the need for better IT governance could be visually motivated. Another reason for the low 
amount of change resistance and the resulting fast implementation of Bita+ was that the stakeholders at Acerta did not look back at the past as being a great success story in terms of controlling and managing IT.

\subsection{Acerta's IT Governance Practices Mapped to the VSM}

\subsubsection{The Corporate Level}

\subsubsection{System 1: Corporate-level Digital Assets and Activities}

The way in which a firm manages its digital assets and activities, e.g. by clustering them in different chunks, will be very different across firms. Being the reason for existence of the IT governance system, these chunks will be identified as 'system 1 operational'-units. As an easy example, an IT governance system of a small firm in which the total set of IT assets is managed in its entirety by a single role or structure, will have a single 'system 1 operational'-unit with its dedicated local management function. Following this logic, seven of these chunks are identified at Acerta, one for each business domain. Indeed, at the corporate level, the total set of digital assets and activities is controlled locally at business domain-level. Each of these separately identified units will need to have a dedicated local management function (as prescribed by the VSM). Hence, seven 'system 1 operational'-units require seven 'system 1 local management'-functions. Accordingly, seven ASCs were identified at Acerta, each responsible for managing their local (business domain-level) digital assets and activities. This results in the fact that at the corporate level, seven embedded viable systems are identified, as the combination of a system 1 operational unit (i.e. a business domain's IT assets) and its dedicated local management function (i.e. the business domain ASC) is an embedded viable system. The total set of these seven embedded viable systems is system 1 of the system-in-focus (i.e. the corporate IT governance system) and therefore can be referred to as the total set of corporate digital assets and activities.

\subsubsection{System 2: Auto-regulatory Coordination}

The more the complexity at the system 1-level (i.e. more system 1 subsystems, or higher coupling/overlap between the different subsystems), the more the need for auto-regulatory coordination mechanisms will be (as these are important variety attenuators for system 3). Business domain 
intersections for IT projects exist at Acerta. Formal agreements are drafted between business domains (for project tasks or sub-projects), to coordinate this overlap.

The EAF was considered by stakeholders to be the most important coordination mechanism to enable the organizational-level cohesion of IT. This is achieved by actively seeking synergies for every new project, thereby eliminating redundancy. The EAF is also responsible for IT-related change management (e.g. by organizing workshops with internal stakeholders). An IT governance section on Acerta's intranet informs internal stakeholders on the way Acerta is governing and managing its IT, with the goal of coordinating internal actions. Acerta also uses standards in the realm of the governance and management of IT, to promote a standardized way of working: e.g. ITIL for IT service management, and Prince2 for IT project management.

There is a crucial difference between auto-regulatory coordination mechanisms (system 2) and mechanisms that work on the command axis (system 3). The formal agreements between two business domains are auto-regulatory, as these are mutual agreements made between two ASCs, not pushed upon them by the executive committee (system 3). Likewise, the EAF would be a system 3 structure if their decisions would be binding. Instead, the EAF has an analytical/advisory function (which is nevertheless in practice almost always followed by the business domains), which makes it a clear example of a system 2 auto-regulatory mechanism. System 2 mechanisms can reflect managerial decisions, but do not make them (Beer, 1985).

Acerta does not make use of activity based costing for their IT, which would be an additional coordination mechanism. Because of this, the ICT support business domain is carrying all the operational costs of run IT. The other six business domains are therefore only carrying the cost of change IT initiatives (including the small fixes). Charge back arrangements like activity based costing, to enable an understanding of the total cost of ownership, are nevertheless identified as a good practice in IT governance literature (De Haes \& Van Grembergen, 2009). The enterprise architect of the supporting business domains critically reflects: "Charge back arrangements would ensure that the other business units would have a better understanding of the real cost of 'run IT', like they do for the 'change IT' initiatives, as these are coming out of their own budgets. For instance, when applications are released, 
it sometimes happens that the old and the new application are running in parallel for another few years, thereby needlessly increasing operational costs. If charge back arrangements were used for these operational costs, these transformations would potentially be a lot smoother, as the business domains would be more inclined to limit these costs."

\subsubsection{System 3, System 3*, and the Command Axis: Ensuring Corporate Cohesion}

The balancing act between local autonomy and cohesion of the whole is central to the VSM. The goal is to maximize local autonomy (of the embedded viable systems), while still ensuring cohesiveness of the whole. This balancing act is the responsibility of system 3, operationalized by the executive committee (and its subcommittees like the risk committee) at Acerta. Therefore, the autonomy of the business domains needs to be balanced against the cohesiveness at the corporate level. The executive committee and its sub-committees make use of the vertical communication channels (resource bargaining, performance measurement, and corporate intervention; together referred to as the command axis) to each ASC, the implementation of self-regulatory coordination mechanisms (system 2), and the occasional IT-related audits (system $3^{*}$ ) to tackle this important task.

Resource bargaining occurs between the executive committee and each individual ASC to decide upon an IT budget for each individual business domain. Performance measurement on IT spending is exercised by the executive committee through the financial controllers that are appointed to the individual business domains. An interesting point here is that the monitoring of IT spend should be combined with the monitoring of realized benefits to have proper benefits management (Lin \& Pervan, 2003). However, the business cases for IT projects at Acerta are rarely used to monitor the realization of expected benefits that might have been described in them. The corporate intervention channel is used to enforce legal \& corporate IT-related requirements (e.g. IT security policies enforced by the risk committee). Failure to comply with these policies is considered a labor offense. This again emphasizes the difference between system 2 coordination mechanisms to auto-regulate and using the command axis to enforce policies. Nevertheless, both approaches are used by system 3 to control the complexity of the digital assets and activities. 
The CIO is a full member of the executive committee at Acerta. This way, the IT issues can be appropriately represented at this level. Indeed, IT needs to be embraced as a strategic partner in a digitized company. Otherwise, there is a clear risk that IT is seen as a cost center (e.g. when the CIO needs to report to the CFO) (De Haes \& Van Grembergen, 2009; Weill \& Ross, 2009).

Acerta operationalizes the audit function (S3*) through multiple practices (e.g. externalized IT audits, monitoring by exception of IT budget consumption, and IT crisis simulations). The identified audit mechanisms obey to the good practices that such mechanisms should adhere to: i.e. they are sporadically used, and all the relevant stakeholders are aware of their existence (Espejo \& Gill, 1997). As such, they also contribute to reducing the remaining variety that system 3 must control through the command axis. System $3^{*}$ can be used when deemed appropriate to check if the information obtained from the ASCs is indeed valid. This is therefore an important variety attenuator for the executive committee, as the ASCs know that these audits will occur eventually.

\subsubsection{4. $\quad$ System 4: Anticipating the Future, Communicating with the Environment, and}

\section{Self-awareness}

Even though Acerta does not claim to be a frontrunner in the continuous application of new IT, the EAF is scanning emerging technologies and actively thinking about potential application opportunities. The enterprise architects follow courses, visit workshops, and have access to technology trend reports, to ensure that they can perform this task. The EAF is therefore responsible for gathering information that needs to be used to prepare Acerta for the future.

Communication with the external stakeholders related to the digital assets and activities happens in multiple ways at Acerta. Transparency about their IT governance to external stakeholders is however not seen as a priority, despite it being an emerging research topic in IT governance literature (De Haes et al., 2017; Joshi et al., 2013) and the possible positive effects it can have for a firm (Chatterjee, Richardson, \& Zmud, 2001). The CIO acknowledged that IT governance information is not included in Acerta's annual report, the preferred medium for IT governance-related disclosure (Joshi et al., 2013), as this document is not deemed very important. This vision of lesser importance of the annual report could potentially be explained by the fact that Acerta is owned by two shareholder groups that each own 
$50 \%$ of the company. This might be very different when a company is publicly listed and has a larger number of minority shareholders. Therefore, Acerta focuses IT governance-related transparency more on their customers, using customer brochures and even allowing the major customers to audit them.

A central spreadsheet of Acerta's IT assets is maintained by the EAF, as well as enterprise architecture models. The enterprise architecture models are however only maintained on an ad-hoc basis, i.e. when a major project is in the preparatory stages a push is observed towards updating these models. Acerta does however not conduct formal IT governance maturity assessments to enable self-awareness of the IT governance system itself. Despite being acknowledged as difficult, it is a good practice to gauge the maturity of IT governance practices, to enable proactive improvements of the system (De Haes \& Van Grembergen, 2015).

\subsubsection{5. $\quad$ S3-S4 Feedback Loop: Balancing the Present and the Future}

At the corporate level, the feedback loop between the present and the future is essentially about Acerta's corporate IT strategic planning. This is a mutual process between different stakeholders (i.e. enterprise architects and the CIO in the EAF (system 4) and managing directors of the different business domains in the executive committee, also including the CIO (system 3)). The EAF, in performing its system 4 function, senses information about the future (e.g. emerging technologies that could potentially transform the sector), while the executive committee (system 3) has clear insights in the present (e.g. in terms of feasibility given the current resources available). Discussions are then held at the executive committee, where the CIO represents the system 4 function (and therefore the process is mutual between system 3 and system 4). The process at the S3-S4 feedback loop at the corporate level ultimately results in a corporate IT strategy (which is in line with the overall business strategy - cfr. Strategic alignment), as well as a corporate IT budget to put this strategy in effect (under the form of a long term financial plan). These strategic choices then dictate the playing field for the lower-level recursions (i.e. the individual business domains). This process is overviewed by system 5 (i.e. operationalized mainly through the supervisory board at Acerta), to ensure that the process of strategic planning is in line with the overall direction, values, and purpose at the corporate level. 
When talking about the S3-S4 feedback loop, the enterprise architect of the supporting business domains indicates: "We have the feeling that a part of these discussions at the EAF remain unheard by the executive committee. The relevant enterprise architect then should discuss this with the managing director of a specific business domain. I think that these discussions could be brought to the executive committee in a more pro-active fashion." This seems to point in the direction of a small imbalance between system 3 and system 4, resulting in the fact that relevant changes in the environment are sometimes ignored (i.e. system 3 slightly dominates system 4) (Achterbergh \& Vriens, 2002). In the context of an IT governance system, the S3-S4 variety loop needs to work particularly well if the organization considers itself to be a frontrunner in the application of new IT. In such cases, the organization will have operationalized system 4 in such a way that it is monitoring the environment for strategic opportunities and threats on a (quasi) continuous basis. Therefore, the connection with system 3 needs to be optimized to be able to quickly respond to these strategic opportunities and threats (e.g. by implementing an emerging technology to stay ahead of the competition). As Acerta claims to be more oriented towards operational reliability, the variety running through this loop will be significantly lower than if it were a company that aimed to be a front-runner in applying new IT. However, if the latter situation were the case, the contemporary arrangement of the S3-S4 feedback loop might be insufficient (i.e. not of requisite variety).

\subsubsection{System 5: Oversight, Direction, Values, and Purpose}

Board-level IT governance is an emerging research topic in the IT governance literature. Despite the agreement between researchers and practitioners alike on the need for board involvement in IT governance, it appears that this is more the exception than the rule in practice (Andriole, 2009; Bart \& Turel, 2010). Nevertheless, board IT oversight and taking up IT-related accountability is required, especially in digitized firms (Valentine \& Stewart, 2013). As Acerta claims to be a digitized firm, we should expect to detect board involvement in IT governance as well. First, we learned that some members of the supervisory board have IT expertise and experience, which is considered to be a good practice to enable board involvement in IT governance (De Haes \& Van Grembergen, 2009; Valentine \& Stewart, 2013). Second, the CIO presents the IT strategy (which is the result of the S3-S4 feedback 
loop) on a yearly basis at the supervisory board. During this meeting, the directors actively ask critical questions. Both issues are linked, as in order to be able to ask critical questions, board members need to have at least some expertise on the business implications of IT (Nolan \& McFarlan, 2005). In VSM terms, the S3-S4 feedback loop indeed needs to be overviewed by system 5. At board level, the importance of major strategic IT projects is not underestimated. For instance, a specific board-level monitoring committee, consisting of several executive board members as well as the CEO, was put in place to monitor the critical strategic IT project new wages engine. The CIO reports to this committee and the committee itself directly reports to the supervisory board.

This concludes the discussion of Acerta's IT governance practices at the corporate level. The IT governance practices that were identified at Acerta are mapped to the VSM (sub)systems or functions and the VSM variety loops. This is summarized by means of Table 4 .

Table 4. Acerta's IT governance practices at the corporate level mapped to VSM systems and variety loops

\begin{tabular}{|c|c|}
\hline $\begin{array}{c}\text { VSM } \\
\text { (sub)systems or } \\
\text { functions }\end{array}$ & IT governance practices at Acerta \\
\hline System 1 & $\begin{array}{l}\text { - Run IT \& Change IT assets divided over the seven business domains (sole } \\
\text { ownership) } \\
\text { - Activity Steering Committee (ASC) for each business domain in charge of } \\
\text { the management of business domain IT assets } \\
\text { - Business domain intersections (e.g. in the context of IT projects) }\end{array}$ \\
\hline System 2 & $\begin{array}{l}\text { - Coordinating business domain intersections by means of formal } \\
\text { agreements between business domains (for project tasks or sub-projects) } \\
\text { - Enterprise Architecture Forum (EAF) for coordinating the different } \\
\text { business domain IT assets, and change management for internal } \\
\text { stakeholders } \\
\text { - IT governance section on Acerta's intranet for coordinating the IT } \\
\text { governance approach } \\
\text { - Standards in the realm of enterprise governance and management of IT: } \\
\text { ITIL (service management) and Prince2 (project management) } \\
\text { - Release management for coordinating the transition from “change IT" to } \\
\text { "run IT” }\end{array}$ \\
\hline System 3 & $\begin{array}{l}\text { - The CIO is a member of the executive committee } \\
\text { - Risk committee as a sub-committee to the executive committee explicitly } \\
\text { dealing with IT-related matters }\end{array}$ \\
\hline
\end{tabular}




\begin{tabular}{|c|c|}
\hline System 3* & $\begin{array}{ll}\text { - } & \text { Externalized IT audit } \\
\text { - } & \text { IT crisis simulations } \\
\text { - } & \text { Monitoring by exception of IT budget consumption (through financial } \\
\text { controllers) }\end{array}$ \\
\hline System 4 & $\begin{array}{l}\text { Enterprise Architecture Forum (EAF) following up on emerging } \\
\text { technologies and their potential applications for Acerta } \\
\text { - Self-awareness: central spreadsheet of IT assets and enterprise architecture } \\
\text { modelling, maintained by the EAF }\end{array}$ \\
\hline System 5 & $\begin{array}{l}\text { - Identity: IT is seen as a business enabler that contributes to business value } \\
\text { - Board-level IT oversight: yearly presentation of the IT strategy to the } \\
\text { supervisory board by the CIO, and IT-related information part of monthly } \\
\text { performance reports } \\
\text { - Supervisory board contains IT expertise and experience } \\
\text { - Directors ask critical IT-related questions, especially regarding the } \\
\text { business implications of IT-related matters } \\
\text { - } \quad \text { New wages engine” board-level monitoring committee (and steering } \\
\text { committee) }\end{array}$ \\
\hline $\begin{array}{c}\text { VSM variety } \\
\text { loops }\end{array}$ & IT governance practices at Acerta \\
\hline $\begin{array}{l}\text { Communication } \\
\text { with the } \\
\text { environment }\end{array}$ & $\begin{array}{l}\text { External communication about enterprise governance and management of } \\
\text { IT to different stakeholders through annual reports, customer brochures } \\
\text { etc. }\end{array}$ \\
\hline Command axis & $\begin{array}{l}\text { - Resource bargaining: Setting business domain IT budget between } \\
\text { executive committee and business domain ASC } \\
\text { - Performance measurement: IT spending monitored by executive } \\
\text { committee through financial controllers } \\
\text { - Corporate intervention: Enforcing legal \& corporate IT-related } \\
\text { requirements (e.g. IT-security requirements enforced by the risk } \\
\text { committee) }\end{array}$ \\
\hline $\begin{array}{l}\text { Algedonic } \\
\text { channel }\end{array}$ & $\begin{array}{l}\text { - Escalation procedures for crisis situations (e.g. incident management } \\
\text { process) }\end{array}$ \\
\hline S3-S4 homeostat & $\begin{array}{l}\text { - IT strategic planning and budget allocation (LTP) between EAF and } \\
\text { executive committee, overviewed by the supervisory board }\end{array}$ \\
\hline
\end{tabular}

\subsubsection{The Business Domain Level}

The ASC of a business domain, being the system 1 local management function, will serve as the metasystem of this next lower-level recursion. This allows us to delve deeper into the governance and management of IT at the business domain level. For instance, there will be a separate viable system for the payroll services business domain. The ASC of payroll services then becomes the metasystem at this recursion. 
Within a given business domain, the digital assets and activities are clustered in two groups, which are managed by different management structures. Accordingly, we find two system 1 subsystems for each business domain: the change IT and the run IT assets and activities. The local management functions of the former are the project steering committees (PSCs), while the local management function of the latter is the maintenance steering committee (MSC) and the business domain’s service meeting.

Auto-regulatory coordination (system 2) within a business domain is established by means of the business domain enterprise architect (who is responsible for the coordination within his/her business domain). Additionally, release management ensures the smooth transitioning from change IT to run IT.

The business domain ASC (system 3) controls the balancing act between local autonomy (of PSCs and MSC) with the cohesion of the whole business domain. It uses system 2 mechanisms, the command axis (resource bargaining, performance measurement, and corporate intervention), and system 3* mechanisms (e.g. project audits) to establish requisite variety.

The domain council (system 4), chaired by the business domain enterprise architect, is responsible for suggesting potential IT-related solution for problem statements that arise within a business domain. It therefore needs to follow-up on emerging technologies, as these can prove valuable solutions. The problem statements and the solution proposed by the domain council are presented at the ASC meeting (system 3). This enables portfolio management and prioritization, which is the implementation of the S3-S4 variety loop within a business domain. This process is mutual between both structures (the enterprise architect is the mutual role). Finally, the business domain managing director overviews this process, to ensure coherence with the overall direction, values, and purpose (of Acerta as well as the business domain).

This concludes the discussion on Acerta's IT governance practices at the business domain level. The IT governance practices that were identified are mapped to the VSM (sub)systems or functions and the VSM variety loops. This is summarized by means of Table 5 .

Table 5. Acerta's IT governance practices at the business domain level mapped to VSM systems and variety loops 


\begin{tabular}{|c|c|}
\hline $\begin{array}{c}\text { VSM } \\
\text { (sub)systems or } \\
\text { functions }\end{array}$ & IT governance practices at Acerta \\
\hline System 1 & $\begin{array}{l}\text { - Project steering committees (PSC) for steering projects } \\
\text { - Maintenance steering committees (MSC) for governing maintenance } \\
\text { budgets and priorities } \\
\text { - Service meeting for monitoring and safeguarding the service quality of } \\
\text { Acerta’s running IT (i.e. service delivery). }\end{array}$ \\
\hline System 2 & $\begin{array}{l}\text { - Release management for the coordination and smooth transitioning from } \\
\text { "change" to "run" } \\
\text { - Enterprise architect responsible for coordination within a business domain }\end{array}$ \\
\hline System 3 & - Business domain ASC \\
\hline System 3* & $\begin{array}{l}\text { - Monitoring by exception of running IT projects } \\
\text { - IT audit and assurance, project audits, etc. }\end{array}$ \\
\hline System 4 & $\begin{array}{l}\text { - Domain council, chaired by the business domain enterprise architect, } \\
\text { conducting pre-studies }\end{array}$ \\
\hline System 5 & 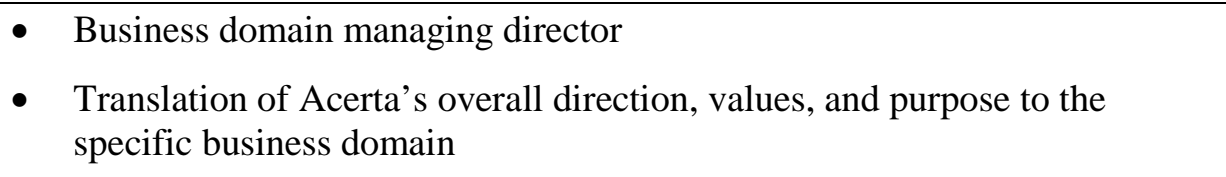 \\
\hline $\begin{array}{l}\text { VSM variety } \\
\text { loops }\end{array}$ & IT governance practices at Acerta \\
\hline $\begin{array}{l}\text { Communication } \\
\text { with the } \\
\text { environment }\end{array}$ & - External communication with business domain-specific customers \\
\hline Command axis & $\begin{array}{l}\text { - Resource bargaining: Division of business domain's IT budget into } \\
\text { categories: investments, projects, functional maintenance, and break \& fix } \\
\text { - Performance measurement: Monitoring budget consumption of MSC and } \\
\text { PSCs } \\
\text { - Corporate intervention: Enforcing IT-related policies }\end{array}$ \\
\hline $\begin{array}{l}\text { Algedonic } \\
\text { channel }\end{array}$ & $\begin{array}{l}\text { - For instance, when certain things in a project go awry, the local } \\
\text { management of a project (i.e. the PSC) can directly report to the ASC in } \\
\text { general and the managing director in specific. }\end{array}$ \\
\hline S3-S4 homeostat & $\begin{array}{l}\text { - Portfolio management and prioritization of projects, overviewed by the } \\
\text { managing director of each business domain }\end{array}$ \\
\hline
\end{tabular}




\subsection{Investigating IT Governance at Acerta using the VSM's Underlying Concepts}

\subsubsection{IT Governance Dynamics: Enabling Viability through Variety Engineering}

The establishment of the supervisory board-level monitoring committee for the new wages engine project is an indication of the dynamic responding behavior of Acerta's IT governance system. This shows the tendency of the metasystem to respond dynamically to changes in operational variety. Specifically, it shows that if the complexity/variety at the level of system 1 increases (in this case a very complex project in the pipeline), the metasystem responds to be able to deal with this increased variety (in this case by increasing the variety of response of system 5 by adding a dedicated monitoring committee, as well as a steering committee to deal with the higher overhead because of the co-sourcing relation).

When probed if such a board-level monitoring structure would be kept in use when the project was finished, the CIO said: "there is a 99\% chance that it will not, but it could definitely be back on the table when another major project arises." Seeing as the VSM is a dynamic model, it is important to recognize that IT governance is a dynamic system. To put it in the words of the IT governance manager: "It should be avoided that the IT governance framework is unable to adapt to changing circumstances. It should not be fully prescribed in detail, as it should also take into account that there are differences between the different business domains for instance. Nevertheless, it always remains a hard requirement that all the IT governance structures bring together business and IT people, to enable them working together closely, to safeguard business/IT alignment and close collaboration.”

Dynamic behavior in response to changes in complexity/variety were observed at Acerta's IT governance system in other areas as well. Several IT governance structures have variable meeting frequencies, depending on the complexity they deal with. For instance, the domain council within a given business domain tends to meet more frequently when there are more, or more complex, projects in the pipeline. A PSC tends to do the same thing depending on the phase the project is in. At the corporate level, the same was observed for the EAF, whose meeting frequency was recently increased 
from every two weeks to every week, as it was acknowledged that Acerta is currently in the process of undergoing some major strategic changes. Additionally, most IT governance structures are not only dynamic in meeting frequencies, but also in composition depending on the issues that need to be discussed. A domain council for instance tends to invite IT architects that are specialists in the technical aspects underlying the issues that are on the agenda for a given meeting. We also observed more dedicated enterprise architects for the more important business domains (in terms of IT budget). The enterprise architect was introduced as a new role within the Bita+ IT governance system, right after the business domain architecture exercise. It was acknowledged that after deciding upon a good business domain architecture, and appointing sole ownership of each element of the IT portfolio to a single business domain, there was a need for a coordination mechanism that enabled the consistency of the whole, resulting in the implementation of the EAF. From a VSM point of view, the implementation of this system 2 mechanism is a way to auto-regulate the variety at the system 1-level (i.e. operational variety), thereby reducing the variety that system 3 is left to deal with. A final point of dynamic behavior in Acerta's IT governance pertains to their business case process. The contents of business cases at Acerta appears to be a function of the investment size and type (e.g. formal business cases are only drafted for projects and investments), as well as the trigger event (e.g. business cases for legal/compliance projects are drafted in less detail).

All previous examples clearly show that Acerta's IT governance system is not set in stone. Rather, it is dynamic in reaction to internal and external disturbances. This trait is the dynamic adaptation capacity (i.e. variety engineering) used to establish requisite variety, thereby enabling viability. A viable IT governance system continues to achieve its purpose of creating and preserving IT business value.

\subsubsection{Unfolding Complexity: Recursions in Acerta's Governance and Management of} IT

The VSM warrants a recursive view on a system. In this paper, two levels of granularity were analyzed, i.e. the corporate level and the business domain level. Following the fractal nature of the VSM, each recursion consists of the same building blocks. However, the operationalization of these elements will be different (as the focus of the system is different). Therefore, different practices will be used to deal 
with the issues at a certain level of granularity. Accordingly, when moving down in recursions (i.e. unfolding complexity), the focus of the system gradually shifts from IT governance to IT management.

A clear flow in the unfolding of complexity can be identified. In Acerta's corporate IT governance system, the identity of the system is held by the board of directors, which is used to overview IT strategic planning and IT budgeting (viz. variety loop S3-S4 at the corporate level). Each ASC then translates what is being asked at executive committee-level to their specific business domain (system 5 at the business domain level). The assigned part of the IT budget is also a given constraint for each business domain, for instance during their specific IT portfolio management and prioritization (S3-S4 variety loop at the business domain level). In turn, the playing field of the MSC and PSCs that belong to a business domain is also determined by the business domain ASC, directly influencing the tasks at that level.

We observed several links between the corporate and the business domain level. First, the managing director of each business domain is also part of the executive committee, which enables them to represent their specific business domain (or subsystem) at the corporate level and allows to maintain a relationship with its containing system. Second, the enterprise architect, who is also the chair of the domain council of his/her business domain, is also part of the EAF at the corporate level, where they operationalize the coordination and intelligence functions of the VSM, bringing together the information they have from within their respective business domains. Third, the algedonic channel (viz. the communication channel used to filter out any information that requires the immediate attention of the metasystem) can be sourced in a PSC and run its way back up to the executive committee and even the supervisory board. This will happen when things go awry in a certain project. Algedonic signals can also be sourced in IT operations. When an incident classified as very high occurs, the incident management system will automatically send an e-mail to the entire executive committee. Finally, business cases for investments can be brought from a business domain's ASC to the executive committee or even the supervisory board at the corporate level. This happens when the IT budget is insufficient but the investment is considered to be of major strategic importance for Acerta. 
In theory, recursions can be defined in both directions, starting from any system-in-focus. In this paper, we first took Acerta's corporate IT governance system as the system-in-focus. One recursion below that, we then identified the business domain-level governance and management of IT. Therefore, seven instances exist at this level for Acerta. One level below the business domain level, we could then for instance define each individual project (i.e. project management system), and each individual project task one level below that. In the other direction, an inter-organizational IT governance system could be defined one level of granularity above the corporate level. Inter-organizational IT governance is an emerging topic in the IT governance body of knowledge, as it is being acknowledged that a lot of collaborative systems exist in the contemporary business environment (Prasad et al., 2012). It should be noted however that Acerta is not involved in such an inter-organizational effort that requires a specific attention for inter-organizational IT governance. If such an inter-organizational IT governance system were to exist, Acerta's overall IT governance system would be a system 1 subsystem of that system, to ensure their representation at the level of the collaborative system.

\subsubsection{Transduction}

Transduction is about reducing possible distortion in communication between different stakeholders in a system (Hoverstadt, 2010). Shared understanding between business and IT stakeholders is key for IT governance (Preston \& Karahanna, 2009). At Acerta, several examples of transduction were detected. For instance, when presenting the IT strategy to the supervisory board (on a yearly basis), the CIO ensured that the business implications of the strategy were clear, as this is the language that the members of the supervisory board speak. Another example can be found in the communication of the risk map. By bringing business and IT roles together in the risk committee, it is ensured that there is a shared understanding when it comes to the IT-related risks and their business implications. Finally, the enterprise architects are also implemented as bridge functions between the business and IT. This way, they for instance translate the technical solutions that are proposed by the ICT architects in a way that business management understands. 


\section{CONCLUSION, LIMITATIONS, AND FUTURE RESEARCH OPPORTUNITIES}

This paper investigated IT governance through Beer's Viable System Model from a theoretical and a practical perspective. The VSM provides a useful lens for studying IT governance for multiple reasons: (1) the complexity of IT governance, (2) the fact that IT governance is dealing with a quickly fluctuating environment, and (3) the fact that IT governance is about controlling digital assets and activities while the VSM is grounded in cybernetics, which is the science of control.

First, this paper theoretically discussed why IT governance can continue to achieve its purpose of creating and preserving IT business value. While prior studies have implied the application potential of the VSM in IS research, including IT governance, this study took a step further in rigorously introducing the VSM to develop a more concrete (cybernetics-based) understanding of IT governance. Drawing theoretical parallels between the VSM and IT governance, we posited that a viable IT governance system (1) needs to timely sense environmental change, and respond readily by reconfiguring the digital assets and activities, and (2) needs to be dynamic in response to the reconfiguration of digital assets and activities. Building on the fundamentals of management cybernetics, IT governance will have these capacities to self-organize through variety engineering, thereby ensuring viability, if the five necessary and sufficient interconnected VSM subsystems (i.e. systems 1 through 5) are accounted for in the IT governance arrangement. A viable IT governance system continues to achieve its purpose of creating and preserving IT business value.

Second, a case study was leveraged to demonstrate how the VSM can be used as a lens for IT governance from a practical perspective. While prior research only approached the issue conceptually, this paper is the first to provide an empirical example of describing and diagnosing IT governance using the VSM. The case study shows how complexity can be unfolded (i.e. at the corporate level and the business domain level) and how variety engineering takes place to handle changing (external and internal) complexity. Accordingly, empirical examples are provided of the VSM-based theoretical arguments that explain why IT governance can continue to achieve its purpose of creating and preserving IT business 
value. For instance, we observed (1) that the new wages engine project was launched to significantly increase payroll processing efficiency, which was deemed necessary to stay competitive with Acerta's core business, and (2) that a supervisory board-level monitoring committee was established because of the resulting increased complexity of the IT project pipeline (i.e. system 1-level). Indeed, these examples show that Acerta has the capacity (1) to sense threats and opportunities in the environment, and respond readily, and (2) to re-organize its IT governance as a response to a change in the IT project pipeline, so that sufficient control over this important strategic project is ensured.

Mapping Acerta's governance and management of IT practices to the VSM, we showed that Acerta operationalized the five necessary and sufficient interconnected VSM subsystems (i.e. systems 1 through 5) in two recursions (i.e. the corporate level and the business domain level). Accordingly, Acerta's IT governance system can self-organize through variety engineering, thereby ensuring viability. A viable IT governance system continues to achieve its purpose of creating and preserving IT business value.

While using the VSM does not provide guidance to select specific IT governance mechanisms, it provides a clear and rigorous mental model for IT governance. It should be recognized that a universal best IT governance solution can never be provided. Instead, appropriate IT governance mechanisms need to be selected (contingent upon the specific organizational context), so that the five necessary and sufficient functions to enable the viability of the system are accounted for. The theoretical parallels drawn in this paper (viz. Table 2) can help in determining the extent to which these functions are accounted for. The empirical part of this paper presents the IT governance mechanisms that Acerta used to operationalize these functions. This provides specific examples for practice regarding which IT governance mechanisms could be used to ensure that these functions are accounted for.

An obvious limitation of this study is the single case study design. Multiple case study research would enable the external validity of the research. A second limitation is related to the effectiveness of the IT governance arrangement. While this article provided cybernetics-based theoretical arguments that explain why IT governance should be arranged a certain way for it to be effective, the effectiveness of the IT governance arrangement was not demonstrated in the case study. Future research steps might 
include a longitudinal analysis of the transformation of an IT governance system, e.g. through action research. The prior situation can then be compared to the new situation (which would be designed using the VSM as a blueprint) in terms of IT governance effectiveness. Alternatively, "extreme case” research can be conducted, by theoretically sampling on a maximal variation on (a) certain dependent variable(s). Potential differences in these measures of IT governance effectiveness can then be related to potential differences at the level of implementation/operationalization of the VSM functions. Finally, design science research could be conducted to present good-practice IT governance solutions for a certain context (e.g. inter-organizational, SME etc.), extensively using practitioner knowledge as well as the IT governance body of knowledge, while rigorously adhering to the VSM. 


\section{ACKNOWLEDGMENT}

The Belgian Agency for Innovation by Science and Technology is acknowledged, as the lead author (Tim Huygh) is being funded through a $\mathrm{PhD}$ grant for strategic basic research at the time of conducting this research.

\section{AUTHOR BIOS}

Tim Huygh is a PhD candidate in Information Technology Governance at the department of Management Information Systems of the Faculty of Business and Economics at the University of Antwerp. He has a bachelor's and master's degree in Business Engineering: Management Information Systems from the University of Antwerp and a master’s degree in Advanced Business Studies from the University of Leuven (KUL).

Steven De Haes, PhD, is Professor Information Systems Management at the University of Antwerp Faculty of Business and Economics and Dean of Antwerp Management School. He is actively engaged in teaching and applied research in the domains of IT Governance \& Management, IT Strategy \& Alignment, IT Value \& Performance Management, IT Assurance \& Audit and Information Risk \& Security. 


\section{REFERENCES}

Achterbergh, J., \& Vriens, D. (2002). Managing viable knowledge. Systems Research and Behavioral Science, 19(3), 223-241.

Ali, S., \& Green, P. (2012). Effective information technology (IT) governance mechanisms: An IT outsourcing perspective. Information Systems Frontiers, 14(2), 179-193.

Anderton, R. (1989). The need for formal development of the VSM. In R. Espejo \& R. Harnden (Eds.), The Viable System Model: Interpretations and Applications of Stafford Beer's VSM (pp. 39-50). John Wiley \& Sons.

Andriole, S. (2009). Boards of Directors and Technology Governance: The Surprising State of the Practice. Communications of the Association for Information Systems, 24, 373-394.

Ashby, W. (1956). An Introduction to Cybernetics. London: Chapman \& Hall.

Bart, C., \& Turel, O. (2010). IT and the Board of Directors: An Empirical Investigation into the "Governance Questions" Canadian Board Members Ask about IT. Journal of Information Systems, 24(2), 147-172.

Beer, S. (1959). Cybernetics and Management. London: The English Universities Press.

Beer, S. (1972). Brain of the firm. London: Allen Lane.

Beer, S. (1979). The heart of enterprise. John Wiley \& Sons.

Beer, S. (1981). Brain of the firm, second edition. Chichester: John Wiley.

Beer, S. (1985). Diagnosing the system for organizations. West Sussex: John Wiley \& Sons.

Beer, S. (1989). The Viable System Model: its provenance, development, methodology and pathology. In R. Espejo \& R. Harnden (Eds.), The Viable System Model: Interpretations and Applications of Stafford Beer's VSM (pp. 11-37). John Wiley \& Sons.

Benaroch, M., \& Chernobai, A. (2017). Operational IT Failures, IT Value Destruction, and Board-Level IT Governance Changes. MIS Quarterly, 41(3), 729-762.

Brown, C. V. (1997). Examining the Emergence of Hybrid IS Governance Solutions: Evidence From a Single Case Site. Information Systems Research, 8(1), 69-94.

Brown, C. V., \& Renwick, J. S. (1996). Alignment of the IS organization. Database, 27(4), 25-33.

Chatterjee, D., Richardson, V. J., \& Zmud, R. W. (2001). Examining the Shareholder Wealth Effects of Announcements of Newly Created CIO Positions. MIS Quarterly, 25(1), 43-70.

Davenport, T. H. (1998). Putting the enterprise into the enterprise system. Harvard Business Review, 76(4), 121-131.

Dawson, G. S., Denford, J. S., Williams, C. K., Preston, D., \& Desouza, K. C. (2016). An Examination of Effective IT Governance in the Public Sector Using the Legal View of Agency Theory. Journal of Management Information Systems, 33(4), 1180-1208.

De Haes, S., Huygh, T., \& Joshi, A. (2017). Exploring the Contemporary State of Information Technology Governance Transparency in Belgian Firms. Information Systems Management, 34(1), 20-37.

De Haes, S., \& Van Grembergen, W. (2009). An Exploratory Study into IT Governance Implementations and its Impact on Business/IT Alignment. Information Systems Management, 26(2), 123-137.

De Haes, S., \& Van Grembergen, W. (2015). Enterprise governance of information technology, second 
edition. Springer.

Espejo, R. (1989). The VSM revisited. In R. Espejo \& R. Harnden (Eds.), The Viable System Model: Interpretations and Applications of Stafford Beer's VSM (pp. 77-100). John Wiley \& Sons.

Espejo, R., \& Gill, A. (1997). The Viable System Model as a Framework for Understanding Organizations. $\quad$ Retrieved from http://www.moderntimesworkplace.com/good_reading/GRRespSelf/TheViableSystemModel.pdf

Espejo, R., \& Harnden, R. (1989). The Viable System Model: Interpretations and Applications of Stafford Beer's VSM. Wiley.

Espejo, R., \& Reyes, A. (2011). Organizational Systems: Managing Complexity with the Viable System Model. Springer-Verlag Berlin Heidelberg.

Flood, R. L., \& Jackson, M. C. (1991). Creative problem solving. Chichester: Wiley.

Gokhale, G. B., \& Banks, D. A. (2004). Organisational Information Security: A Viable System Perspective. In Proceedings of the 2nd Australian Information Security Management Conference 2004 (pp. 178-184).

Gregor, S. (2006). The Nature of Theory in Information Systems. MIS Quarterly, 30(3), 611-642.

Herring, C., \& Kaplan, S. (2001). The viable system architecture. In Proceedings of the 34th Annual Hawaii International Conference on System Sciences (pp. 1-10). IEEE Comput. Soc.

Hobbs, G., \& Scheepers, R. (2009a). Identifying capabilities for the IT function to create agility in information systems. In PACIS 2009 Proceedings (p. 20).

Hobbs, G., \& Scheepers, R. (2009b). Identifying capabilities for the IT function to create agility in information systems. In PACIS 2009 Proceedings.

Hoverstadt, P. (2010). The Viable System Model. In M. Reynolds \& S. Holwell (Eds.), Systems Approaches to Managing Change: A Practical Guide (pp. 87-133). London: Springer.

Huang, R., Zmud, R. W., \& Price, R. L. (2009). IT Governance Practices in Small and Medium-Sized Enterprises: Recommendations from an Empirical Study. In Information Systems - Creativity and Innovation in Small and Medium-Sized Enterprises (pp. 158-179). Springer Berlin Heidelberg.

ISACA. (2012). COBIT 5: A Business Framework for the Governance and Management of Enterprise IT. Retrieved from http://www.isaca.org/COBIT/Pages/COBIT-5-Framework-product-page.aspx

ISO/IEC. (2008). ISO/IEC Standard 38500: Corporate Governance of Information Technology.

IT Governance Institute (ITGI). (2003). Board Briefing on IT Governance, 2nd Edition. Retrieved from http://www.isaca.org/knowledge-center/research/researchdeliverables/pages/board-briefing-on-itgovernance-2nd-edition.aspx

Jackson, M. C. (1991). Systems methodology for the management sciences. New York: Plenum Press.

Jackson, M. C. (2000). Systems Approaches to Management. New York: Kluwer Academic/Plenum Publishers.

Joshi, A., Bollen, L., \& Hassink, H. (2013). An Empirical Assessment of IT Governance Transparency: Evidence from Commercial Banking. Information Systems Management, 30(2), 116-136.

Karayaz, G., Keating, C. B., \& Henrie, M. (2011). Designing Project Management Systems. In 44th Hawaii International Conference on System Sciences (p. 10). IEEE.

Kearns, G. S., \& Sabherwal, R. (2006). Strategic Alignment Between Business and Information Technology: A Knowledge-Based View of Behaviors, Outcome, and Consequences. Journal of Management Information Systems, 23(3), 129-162. 
Laumann, M., \& Rosenkranz, C. (2008). Analysing Information Flows for Controlling Activities within Supply Chains: An Arvato (Bertelsmann) Business Case. In ECIS 2008 Proceedings.

Lewis, E., \& Millar, G. (2009). The Viable Governance Model - A Theoretical Model for the Governance of IT. In 42nd Hawaii International Conference on System Sciences (pp. 1-10). IEEE.

Lin, C., \& Pervan, G. (2003). The practice of IS/IT benefits management in large Australian organizations. Information \& Management, 41(1), 13-24.

Mingers, J., \& White, L. (2010). A review of the recent contribution of systems thinking to operational research and management science. European Journal of Operational Research, 207(3), 11471161.

Nolan, R., \& McFarlan, F. (2005). Information technology and the board of directors. Harvard Business Review, 83(10), 96-106.

Overby, E., Bharadwaj, A., \& Sambamurthy, V. (2006). Enterprise agility and the enabling role of information technology. European Journal of Information Systems, 15(2), 120-131.

Peppard, J. (2005). The Application of the Viable Systems Model to Information Technology Governance. In ICIS 2005 Proceedings.

Peterson, R. R. (2004a). Crafting Information Technology Governance. Information Systems Management, 21(4), 7-22.

Peterson, R. R. (2004b). Integration Strategies and Tactics for Information Technology Governance. In Strategies for information technology governance (pp. 37-80).

Pollalis, Y. A., \& Dimitriou, N. K. (2008). Knowledge management in virtual enterprises: A systemic multi-methodology towards the strategic use of information. International Journal of Information Management, 28(4), 305-321.

Prasad, A., Green, P., \& Heales, J. (2012). On IT governance structures and their effectiveness in collaborative organizational structures. International Journal of Accounting Information Systems, 13(3), 199-220.

Preece, G., Shaw, D., \& Hayashi, H. (2013). Using the Viable System Model (VSM) to structure information processing complexity in disaster response. European Journal of Operational Research, 224(1), 209-218.

Preston, D. S., \& Karahanna, E. (2009). Antecedents of IS Strategic Alignment: A Nomological Network. Information Systems Research, 20(2), 159-179.

Pykäläinen, T., Yang, D., \& Fang, T. (2009). Alleviating piracy through open source strategy: An exploratory study of business software firms in China. The Journal of Strategic Information Systems, 18(4), 165-177.

Raghupathi, W. (2007). Corporate Governance of IT: A Framework For Development. Communications of the ACM, 50(8), 94-99.

Richter, J., \& Basten, D. (2014). Applications of the Viable Systems Model in IS Research -- A Comprehensive Overview and Analysis. In 47th Hawaii International Conference on System Sciences (pp. 4589-4598). IEEE.

Sambamurthy, V., Bharadwaj, A., \& Grover, V. (2003). Shaping Agility through Digital Options: Reconceptualizing the Role of Information Technology in Contemporary Firms. Management Information Systems Quarterly, 27(2), 237-263.

Sambamurthy, V., \& Zmud, R. (1999). Arrangements for Information Technology Governance: A Theory of Multiple Contingencies. Management Information Systems Quarterly. Retrieved from http://aisel.aisnet.org/misq/vol23/iss2/6 
Shaw, D. R., Snowdon, B., Holland, C. P., Kawalek, P., \& Warboys, B. (2004). The viable systems model applied to a smart network: the case of the UK electricity market. Journal of Information Technology, 19(4), 270-280.

Skeivys, R. (2016). Governance of IT and cybernetics. In Norbert Wiener in the 21st Century (21CW), 2016 IEEE Conference on (pp. 46-49). Melbourne, Australia: IEEE.

Turel, O., \& Bart, C. (2014). Board-level IT governance and organizational performance. European Journal of Information Systems, 23(2), 223-239.

Valentine, E., \& Stewart, G. (2013). The emerging role of the Board of Directors in enterprise business technology governance. International Journal of Disclosure and Governance, 10(4), 346-362.

Valentine, E., \& Stewart, G. (2015). Enterprise Business Technology Governance: Three Competencies to Build Board Digital Leadership Capability. In 48th Hawaii International Conference on System Sciences (pp. 4513-4522). IEEE.

Van Grembergen, W., \& De Haes, S. (2009). Enterprise Governance of Information Technology: Achieving Strategic Alignment and Value. Springer.

Weill, P., \& Ross, J. W. (2004). IT Governance: How Top Performers Manage IT Decision Rights for Superior Results. Harvard Business Press.

Weill, P., \& Ross, J. W. (2009). IT savvy: what top executives must know to go from pain to gain. Harvard Business Press.

Wiener, N. (1948). Cybernetics. Paris: Hermann.

Wilkin, C. L., Campbell, J., \& Moore, S. (2013). Creating value through governing IT deployment in a public/private-sector inter-organisational context: a human agency perspective. European Journal of Information Systems, 22(5), 498-511.

Winkler, T. J., \& Brown, C. V. (2013). Horizontal Allocation of Decision Rights for On-Premise Applications and Software-as-a-Service. Journal of Management Information Systems, 30(3), 1348.

Wu, S. P.-J., Straub, D. W., \& Liang, T.-P. (2015). How information technology governance mechanisms and strategic alignment influence organizational performance: insights from a matched survey of business and IT managers. MIS Quarterly, 39(2), 497-518.

Yin, R. K. (2014). Case Study Research: Design and Methods, 5th edition. SAGE Publications, Inc.

Yolles, M. (1999). Management Systems. London: Financial Times Ltd. 